\title{
Rapidly Measuring Reactivities of Carboxylic Acids to Generate Equireactive Building Block Mixtures: A Spectrometric Assay
}

\author{
Kendra L. Dombi, Ulrich E. Steiner, and Clemens Richert* \\ Department of Chemistry, University of Constance, 78457 Konstanz, Germany
}

\begin{abstract}
The relative reactivity of building blocks is critical for a successful preparation of combinatorial libraries. Here, we present a method for measuring the reactivity of carboxylic acid building blocks in amide-forming reactions. The method involves competitive reactions between a reference and test acid and a tetraphenylporphyrin reaction partner with four reactive sites. Relative reactivities are calculated on the basis of the distribution of substituted porphyrins found in MALDI-TOF mass spectra. Reactivities thus determined were used to prepare reactivity-adjusted building block mixtures. These were reacted with amino-terminal oligonucleotide and peptide scaffolds on solid support, generating small libraries suitable for spectrometrically monitored selection experiments (SMOSE). The rate of building block "drop outs" that fail to couple as expected was not substantially lowered by acquiring spectra from two reactions, performed with different ratios of building blocks, where the effect of a given substituent on the desorption/ionization yield of the porphyrin can be eliminated. Instead, coupling building blocks of similar size together or employing $\mathrm{N}$-hydroxysuccinimide esters rather than activating with a "uronium salt" were found to improve the quality of libraries generated via competitive reactions.
\end{abstract}

\section{Introduction}

Rate constants provide fundamental information on chemical reactions. This information is particularly important for combinatorial syntheses. Where more than one product is to be generated in one experiment, relative rate constants should ideally be known to adjust reactions conditions such that all desired products are formed efficiently. Until now, it has been difficult to predict chemical reactivities accurately. Linear free enthalpy relationships have improved our understanding of the factors governing reactivity. ${ }^{1}$ Still, steric, electronic, and stereoelectronic factors, not to mention solvation, are difficult to parametrize with the degree of accuracy required to predict rate constants reliably for all members of a diverse set of building blocks. Databases of failed reactions are beginning to emerge, ${ }^{2}$ enriching the prediction approaches, but being costly, these are not available to most research laboratories. Therefore, the reactivity of new building blocks often has to be determined experimentally prior to employing them in reactions with precious scaffolds or intermediates.

In a recent review on analytical techniques for reaction optimization, ${ }^{3}$ the authors lamented the fact that despite the widespread use of combinatorial chemistry for the synthesis of new compounds, the optimization of reactions is still largely performed using traditional methods. In fact, for new building blocks, the most common way of gauging their reactivity is iterative via determining whether the desired products are formed in sufficient yield. Particularly in bead-

* To whom correspondence should be addressed at his current address: Institut für Organische Chemie, Universität Karlsruhe (TH), Fritz-HaberWeg 6, D-76131 Karlsruhe, Germany. Tel: 49 (0)721 608 2091. E-mail: cr@rrg.uka.de. based assays, this approach can be problematic, since usually not all compounds made are being characterized. If individual compounds are being synthesized and characterized, yield and purity obtained do not suffice for calculating a rate constant required to plan future syntheses. If one wishes to synthesize libraries via reactions with mixtures of building blocks, the lack of reactivity data can lead to particularly disappointing results, with libraries very far from equimolar representation of the desired products being formed.

Several approaches have been reported to overcome this problem. Houghten and collaborators have determined the relative reactivities of amino acid building blocks, ${ }^{4}$ building on earlier work from the 1970s. ${ }^{5}$ By performing mixed couplings and determining the amino acid composition of the resulting libraries and repeating the procedure through several "cycles", they obtained reactivity scores the translation of which into equireactive building block mixtures gave roughly equal incorporation of all amino acid residues employed. Gerritz and collaborators employed competitive reactions to obtain Hammett relationships for reactions on different solid supports, thus allowing them to predict the relative rates of reactions with substrates. ${ }^{6}$ Others have developed spectroscopic ${ }^{7,8}$ and spectrometric ${ }^{9}$ techniques for monitoring reactions or analyzing the results of combinatorial syntheses efficiently.

If competitive reactions are performed under pseudo-firstorder conditions, product distribution can yield relative reactivities. The analytical technique for measuring product composition in such reactivity tests should ideally use little material and should be rapid, reliable, and automatable. Mass spectrometric analysis of reactions performed on the nanomole scale fulfills several of these criteria, as evidenced by 
the popularity of mass spectrometry for characterizing and screening combinatorial libraries..$^{10}$ MALDI-TOF mass spectrometry is particularly well-suited, since spectra can often be acquired without any time-consuming and potentially biasing workup. There are, however, several problems with MALDI as the read-out technique for reactions involving small molecules. Usually, the signals of small molecules are in a region where matrix ions dominate the spectrum, ${ }^{11}$ the desorption/ionization varies greatly with the structure of the analytes, and the vapor pressure of small molecules may be so high that they evaporate prior to laser-induced desorption/ ionization. Even if these drawbacks were not critical, it is important to remember that signal intensity in MALDI-TOF mass spectra does not necessarily correlate with concentration unless conditions for quantitative detection have been established. ${ }^{12-15}$

In a recent preliminary research note published electronically, ${ }^{16}$ we presented a method for measuring the relative reactivity of pairs of activated carboxylic acids used to synthesize tetraphenylporphyrin libraries. The method employs a tetrakis(aminoacylanilino)porphyrin as reaction partner and MALDI-TOF mass spectrometry as the analysis method for product analysis of competitive reactions. The method takes advantage of several features of the tetraphenylporphyrin scaffold: (i) that it shifts the $\mathrm{m} / \mathrm{z}$ of the pseudomolecular peaks into a mass range free of interference from matrix ions; (ii) its desorption properties dominate those of the products prepared, making the desorption/ionization properties less dependent on the structure of the substrate to be reacted; (iii) it produces strong signals in MALDI-TOF mass spectra; (iv) it is chemically very stable and resists fragmentation; (v) it offers four essentially independent reaction sites, improving the dynamic range of the mass spectrometrical reactivity determination; and (vi) it makes products visible with the naked eye, making them easy to trace and quantify.

However, the method presented ${ }^{16}$ also had a number of drawbacks, such as being limited to adjusting the reactivity of pairs of building blocks, without yielding rate constants that could be employed for planning the syntheses of larger libraries. Further, the method had been tested on no more than seven building blocks and only porphyrins as the targets for library generation. Here, we report on a reactivity test system that allows one to derive rate constants for building blocks. The reactivities thus determined were employed successfully for generating small libraries of modified oligonucleotides and peptides using mixtures of structurally diverse building blocks.

\section{Results}

As discussed above, a porphyrin was to act as the reaction partner for the building blocks to be tested for their reactivity. To obtain a set of products whose relative concentration allows direct calculation of relative reactivities, the porphyrin had to have several reaction sites. This led to the $p$-substituted tetraphenylporphyrin as scaffold. Scheme 1 shows the synthesis of the tetraphenylporphyrins that were employed in the reactivity tests. Starting from meso-tetrakis(p-aminophenyl)porphyrin (1), available from $p$-nitrobenzaldehyde
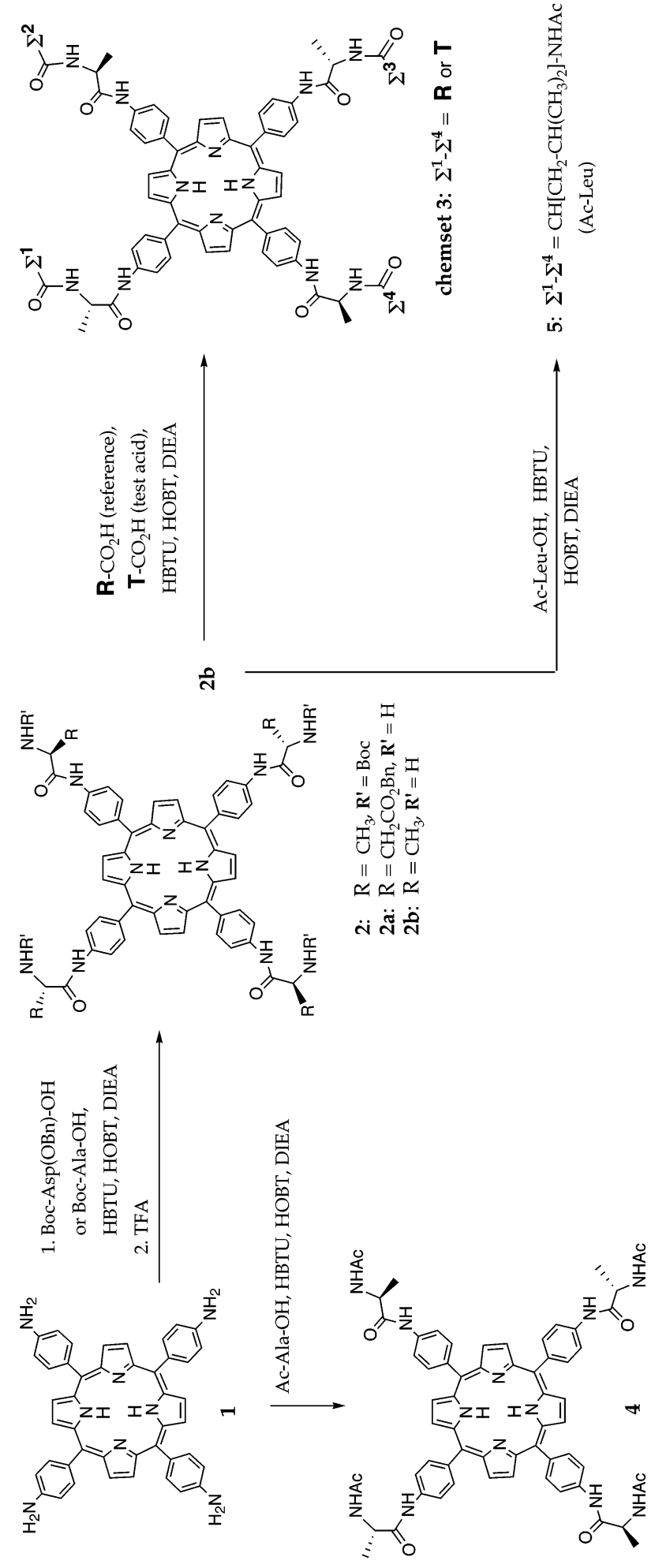
Scheme 2

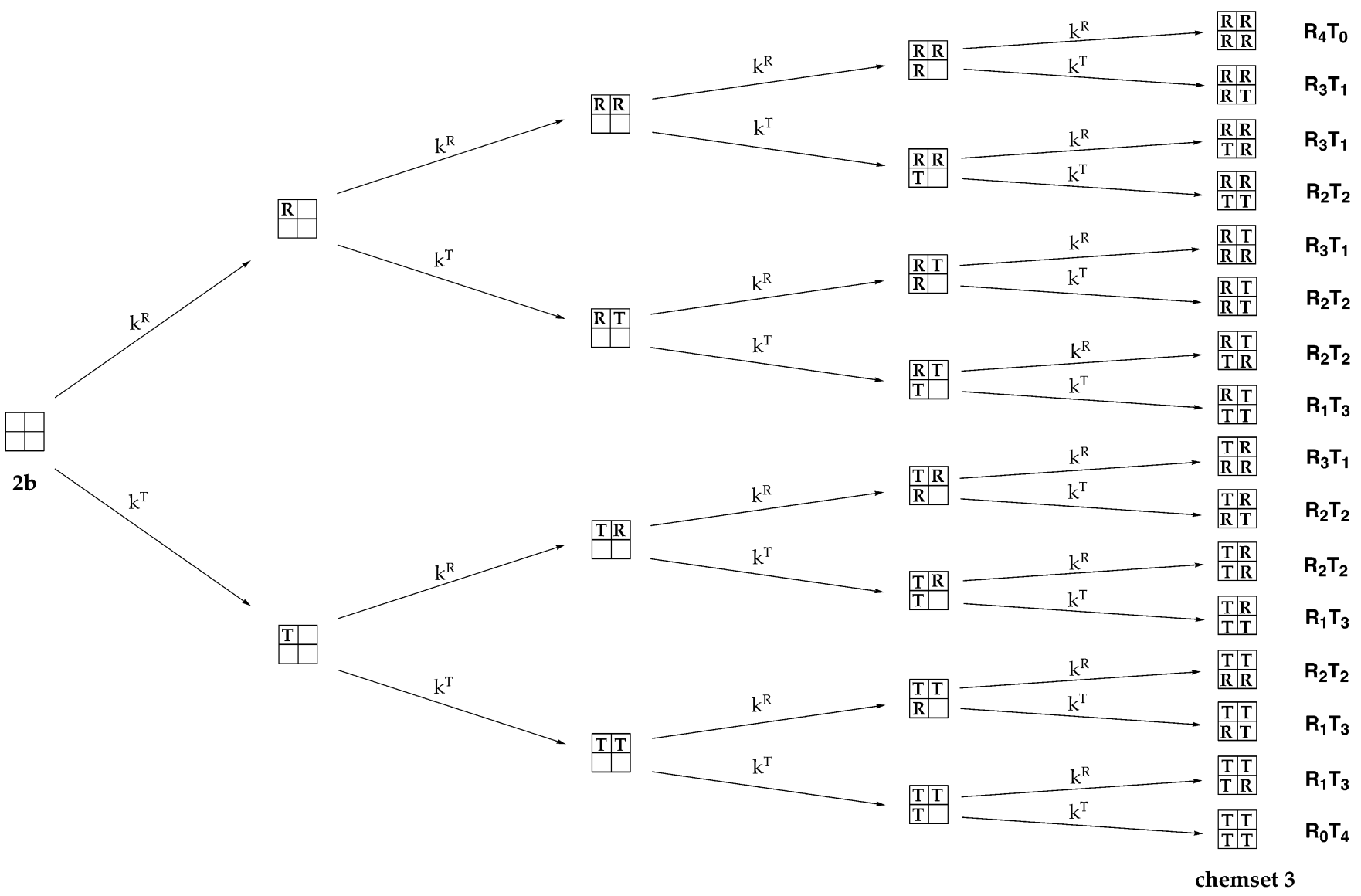

and pyrrole in two steps, ${ }^{17} \mathrm{N \alpha}$-Boc-aspartic acid $\gamma$-benzyl ester or $N \alpha$-Boc-alanine were coupled to produce protected acylamidoporphyrins, whose Boc-deprotection with TFA yielded $\mathbf{2} \mathbf{a}^{16}$ and $\mathbf{2} \mathbf{b}$, respectively. Exploratory coupling reactions with $\mathbf{2 a}$ and activated carboxylic acids of low reactivity showed side products presumably resulting from aspartimide formation. Therefore, $\mathbf{2 b}$, whose side chain is unreactive, was used in all subsequent work.

Reactions of tetraamine $\mathbf{2} \mathbf{b}$ with activated acids led to product chemsets 3 (Scheme 1), the composition of which was measured via MALDI-TOF mass spectrometry under conditions previously shown to allow quantitative detection of tetraphenylporphyrins. ${ }^{18}$ To ensure pseudo-first-order conditions, 84 equiv of acids was used. Scheme 2 shows the reaction pathways that $\mathbf{2} \mathbf{b}$ can follow to produce the components of chemset 3 . In this scheme, a square with its four boxes represents one porphyrin molecule, whose terminal amino groups are either unreacted (open box) or have been acylated with the residue of the reference acid (box with an $\mathrm{R}$ ) or with the residue of the test acid (box with a $\mathrm{T}$ ). Whether a reaction occurs with the reference acid or the test acid is indicated by $k^{\mathrm{R}}$ or $k^{\mathrm{T}}$ on the reaction arrows, respectively.

All but 5 of the 16 end products formed in the reactions shown in Scheme 2 are isobaric, i.e., have the same mass. The left-hand side of Figure 1 shows a cartoon of the MALDI spectrum of chemset 3 expected for a reaction in which two acids are equireactive. On the basis of binominal statistics, relative peak heights of 1:4:6:4:1 should be found. On the right-hand side of Figure 1, the spectrum expected for a coupling reaction with a reference acid that is twice as reactive as the test acid is drawn. Here, peak intensity ratios of 16:32:24:8:1 result. The relative reactivity ratio of 2 is reflected in every ratio between neighboring peaks, i.e., 16: 32 is twice as large as 1:4, 32:24 is twice as large as 4:6, etc. Measuring the intensity of any pair of neighboring peaks in a mass spectrum should, therefore, in principle allow determination of the relative reactivity of a test acid compared to a reference acid.

To validate our method for quantitative detection ${ }^{18}$ for the present type of tetraphenylporphyrins, calibration experiments were performed with $\mathrm{N}$-acetylalanine-substituted 4 (Scheme 1) as internal standard and $\mathbf{5}$ as analyte. With a matrix of 2,4,6-trihydroxyacetophenone monohydrate (THAP) and diammonium citrate, ${ }^{19}$ together with high laser power and at least 100 laser shots/spectrum, ${ }^{15,18}$ linearity with an $r^{2}$ value of 0.991 was observed in the concentration range of interest (Figure 2a). At concentrations above $60 \mu \mathrm{M}$ of $\mathbf{5}$, the expected $^{15}$ saturation effect was observed (Figure $2 b$ ). This calibration experiment established the linearity of the correlation between relative peak intensity and concentration, but not an absolute calibration for any tetrakis(acylamidoanilino)porphyrin, unless the change in desorption and ionization properties between individual porphyrin species were negligible. Depending on the substituents, the slopes of the calibration functions may differ from porphyrin to porphyrin, but earlier experience shows that linearity can be expected over the concentration range of interest. ${ }^{18}$

The assay shown schematically in Figure 3 (assay 1) was performed with a number of structurally diverse carboxylic 


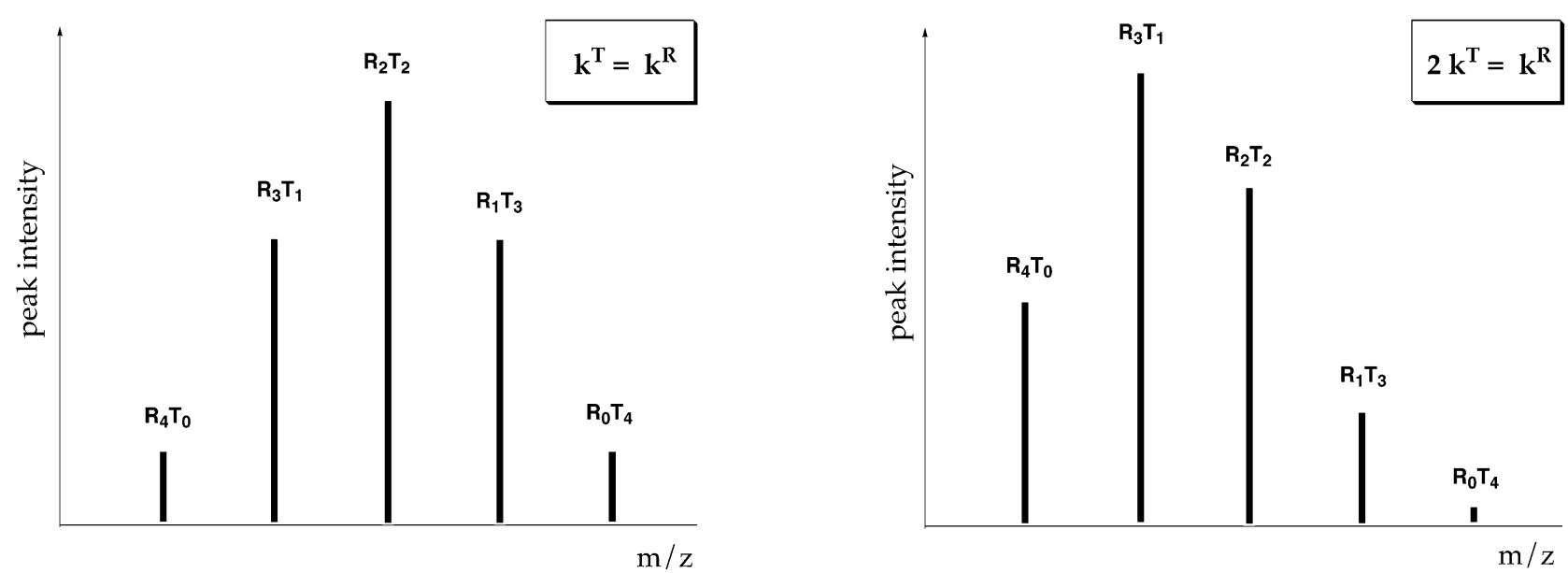

Figure 1. Graphs of mass spectra expected for porphyrin libraries of general structure chemset $\mathbf{3}$ generated in reactions with reference and a test acid of identical reactivity (left-hand side) or with test acid one-half as reactive as the reference acid (right-hand side).
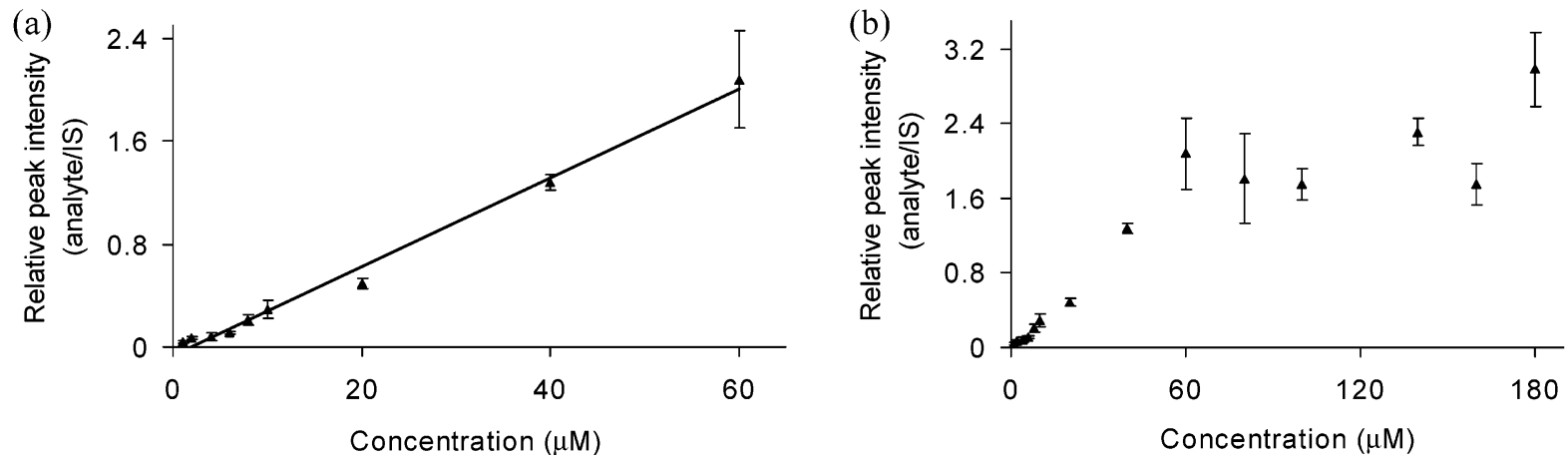

Figure 2. Calibration plots for the quantitative detection of porphyrin $\mathbf{5}$ via MALDI-TOF mass spectrometry with tetrakis(acetylalanylaniline)porphyrin $\mathbf{4}$ as internal standard (a) for the concentration range of interest and (b) up to a concentration range where saturation is observed.

R- $\mathrm{CO}_{2} \mathrm{H}=$ Ac-Leu-OH (reference acid)

stock solutions $(0.13 \mathrm{M})$

T- $\mathrm{CO}_{2} \mathrm{H}$ (test acid)

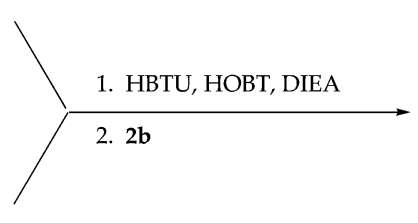

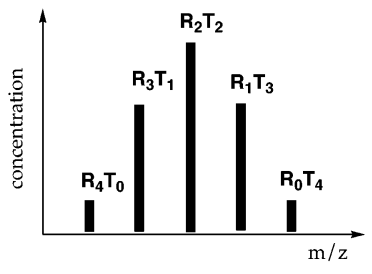

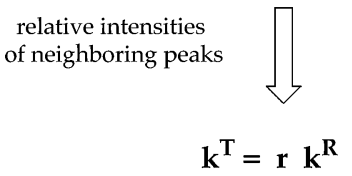

Figure 3. Schematic drawing of reactivity test termed "assay 1".

acid building blocks $\left(\mathrm{T}-\mathrm{CO}_{2} \mathrm{H}\right)$ and $\mathrm{N \alpha}$-acetyl-L-leucine as reference acid $\left(\mathrm{R}-\mathrm{CO}_{2} \mathrm{H}\right)$. For this, an equimolar mixture of the two acids was generated from stock solutions in DMF, to which a solution of 2-(1H-benzotriazole-1-yl)-1,1,3,3tetramethyluronium hexaflourophosphate (HBTU) and hydroxybenzotriazole monohydrate (HOBT) in DMF was added, followed by addition of Hünig's base (DIEA). This form of activation was chosen because it ensures rapid reactions, even when the amine is immobilized on nonswellable supports, such as controlled-pore glass (CPG). ${ }^{20}$ It has the disadvantage, however, of activating carboxylic acids in a multistep process in which each step may be proceeding with different rates for the competing acids, such that the conversion to HOBT esters could be completed for the most reactive acid at a time when the least reactive acid is still partially unactivated. To alleviate this problem at least in part, the activation reaction was allowed to proceed for $10 \mathrm{~min}$ prior to addition of the solution to $\mathbf{2} \mathbf{b}$. In addition, 0.9 equiv of HBTU was used, since an excess of this "uronium salt" was found to react with the amines, producing side products with a mass $98 \mathrm{Da}$ higher than that of the respective amines.

In the simplest form of the assay, a single spectrum of the product mixture was acquired. A typical spectrum yielded more than one pair of neighboring peaks in the MALDI spectrum, over which one could average. To put assay 1 to the test, a first series of experiments was performed with acids of increasing steric bulk. A typical spectrum of the products from an assay with isobutyric acid as $\mathrm{R}-\mathrm{CO}_{2} \mathrm{H}$ is shown in Figure 4. The results from all four acids tested are compiled in Table 1 . While pivalic acid coupled to a very small extent in the competitive reaction, indicating that it 


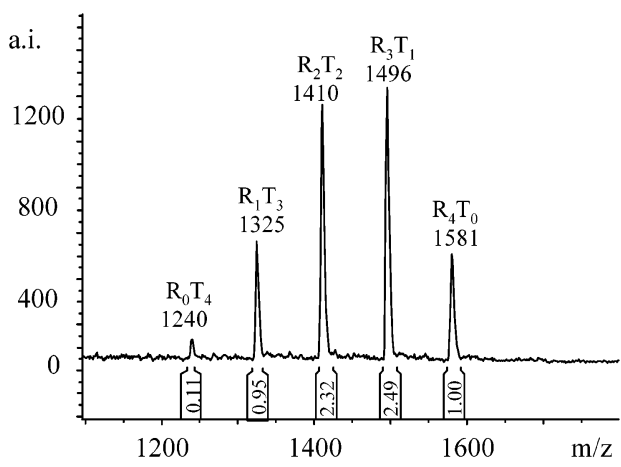

Figure 4. Representative MALDI-TOF mass spectrum of a porphyrin library of general structure chemset $\mathbf{3}$ generated in a reactivity assay of format assay 1 with isobutyric acid as $\mathrm{T}-\mathrm{CO}_{2} \mathrm{H}$ and Ac-Leu-OH as $\mathrm{R}-\mathrm{CO}_{2} \mathrm{H}$. The labels on the peaks indicate what number of each of the two acid residues are present in the porphyrin causing the peak.

Table 1. Relative Reactivity ( $r$ ) of Carboxylic Acids in Competitive Coupling Assays with Ac-Leu-OH as Reference Acid, According to Format of Assay 1 (Figure 3)

\begin{tabular}{llc}
\hline \multicolumn{1}{c}{$\mathrm{T}-\mathrm{CO}_{2} \mathrm{H}$} & $\begin{array}{c}\text { statistically corrected } \\
\text { relative peak intensities } \\
\text { of neighboring peaks }\end{array}$ & $\begin{array}{c}{ }^{a} \\
\text { relative } \\
\text { reactivity }(r)^{b}\end{array}$ \\
\hline $\mathrm{CH}_{3} \mathrm{CO}_{2} \mathrm{H}$ & $0.85 / 0.94 / 0.94 / 0.94$ & 0.92 \\
$\mathrm{CH}_{3} \mathrm{CH}_{2} \mathrm{CO}_{2} \mathrm{H}$ & $0.91 / 0.95 / 0.97 / 0.98$ & 0.95 \\
$\left(\mathrm{CH}_{3}\right)_{2} \mathrm{CHCO}_{2} \mathrm{H}$ & $0.51 / 0.63 / 0.62 / 0.61$ & 0.59 \\
$\left(\mathrm{CH}_{3}\right)_{3} \mathrm{CCO}_{2} \mathrm{H}$ & $-/-/-/ 0.03$ & 0.03 \\
\hline
\end{tabular}

${ }^{a}$ Based on the relative peak intensity distribution 1:4:6:4:1 (see Figure 1) ${ }^{b}$ Average of the values determined from the relative peak intensities.

was less reactive than Ac-Leu-OH by a factor of at least 30, the remaining three acids did compete successfully enough to detect a set of products containing their residues. Unexpectedly, sterically unhindered acetic and propionic acid showed reactivity similar to the Ac-Leu-OH (the carboxylic acid group of which is electronically activated through the acetamido substituent). When the assay was repeated for isobutyric acid, the same relative reactivity was obtained within $10 \%$, indicating reasonable reproducibility.

To place the relative reactivities $(r)$ in a quantitative context, Ac-Leu-OH was reacted alone with $\mathbf{2 b}$ at sufficient dilution to measure the conversion of the first $10 \%$ of $\mathbf{2 b}$ to the singly acylated porphyrin (initial rate approach) without noticeable formation of higher coupling products. The rate constant for the coupling reaction thus obtained was $213 \mathrm{M}^{-1}$ $\mathrm{min}^{-1}$. The absolute rate constants for the test acids may be obtained from this value by multiplying by the relative reactivity number.

Next, a series of reactivity assays was performed with benzoic acid and para-substituted benzoic acid derivatives for which Hammett $\sigma$ values were known. ${ }^{21}$ The series included benzoic acid itself and its derivatives with $p$-nitro, $p$-cyano, $p$-bromo, $p$-chloro, $p$-methyl, and $p$-methoxy substituents. Plotting the logarithm of the relative reactivities against the $\sigma$ values yielded the expected linear free enthalpy relationship (Figure 5). Only the value for the methoxy derivative deviated significantly from this correlation.

Assay 1 was then performed with a set of structurally diverse carboxylic acids. All compounds tested in this phase of the project are shown in Figure 6. Figure 7 shows three

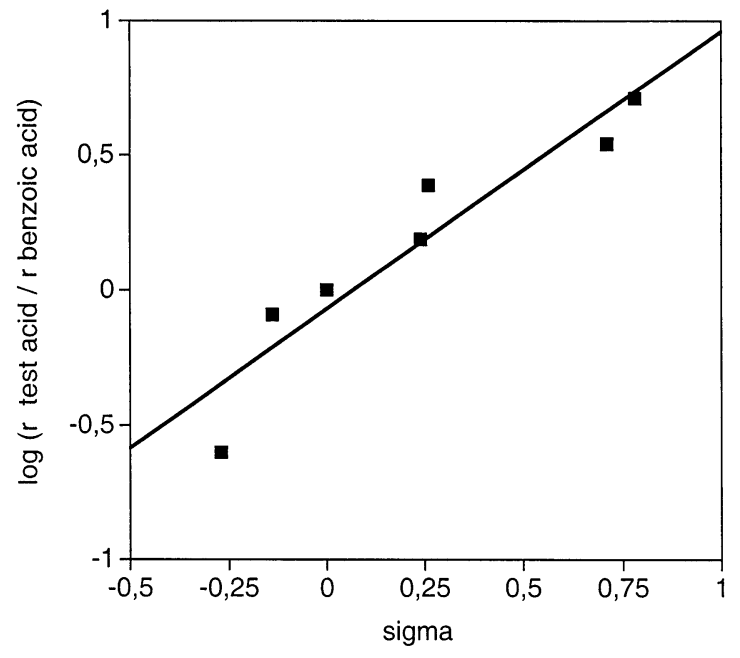

Figure 5. Hammet plot of the results from reactivity assays of the format assay 1 with different benzoic acids and Ac-Leu-OH as reference acid $\left(\mathrm{R}-\mathrm{CO}_{2} \mathrm{H}\right)$. The para substituents of the carboxylic acids coupled are $-\mathrm{NO}_{2},-\mathrm{CN},-\mathrm{Br},-\mathrm{Cl},-\mathrm{H},-\mathrm{CH}_{3}$, and $-\mathrm{OMe}$.

typical spectra for reactions in which the test acid was less reactive (a), of similar reactivity (b), and more reactive than acetyl leucine (c). The relative reactivities measured against acetyl leucine via assay 1 are compiled in the second column of Table 2. The relative reactivities of the building blocks range from 0.11 (adamantane carboxylic acid) to 3.43 (naphthoxyacetic acid).

Acids of similar reactivity were grouped together without regard to their structure, but avoiding similar molecular weights and thus peak overlap in mass spectra. This grouping by similar reactivity prevented the amount of the most reactive building blocks from having to be adjusted to understoichiometric values over the amines of the scaffold. Each group was then tested for its ability to generate a library in mixed coupling reactions with oligonucleotide scaffold $\mathbf{6}$ (Scheme 3). Oligonucleotide $\mathbf{6}$ had been generated from nucleoside-bearing controlled-pore glass 7 via standard solidphase synthesis using the phosphoramidite protocol. The last extension cycle of the DNA synthesis employed the protected phosphoramidite of $5^{\prime}$-amino-5'-deoxythymidine $(\mathbf{8})$, the reaction of which with 9 yielded 6 under conditions previously reported..$^{22}$ The competitive couplings produced protected chemsets 4 , whose deprotection with concentrated aqueous ammonia at room temperature liberated chemsets 5. Figure $8 \mathrm{a}$ shows a representative MALDI spectrum (library 7). The fourth column of Table 2 gives the relative peak intensities obtained for the libraries of general structure chemset 5. It should be noted that peak height measurements gave slightly better results for products such as library 7 than the peak intensities reported, which are based on peak integration. However, integration has proven easier to automate and generally gives similar results in quantitative MALDI-TOFMS. ${ }^{15}$ Though the results for chemset 5 show that all but two acids did couple detectably, a number of acids gave peaks considerably more or less intense than the rest of the products, indicating that they were more or less reactive than expected on the basis of the results from assay 

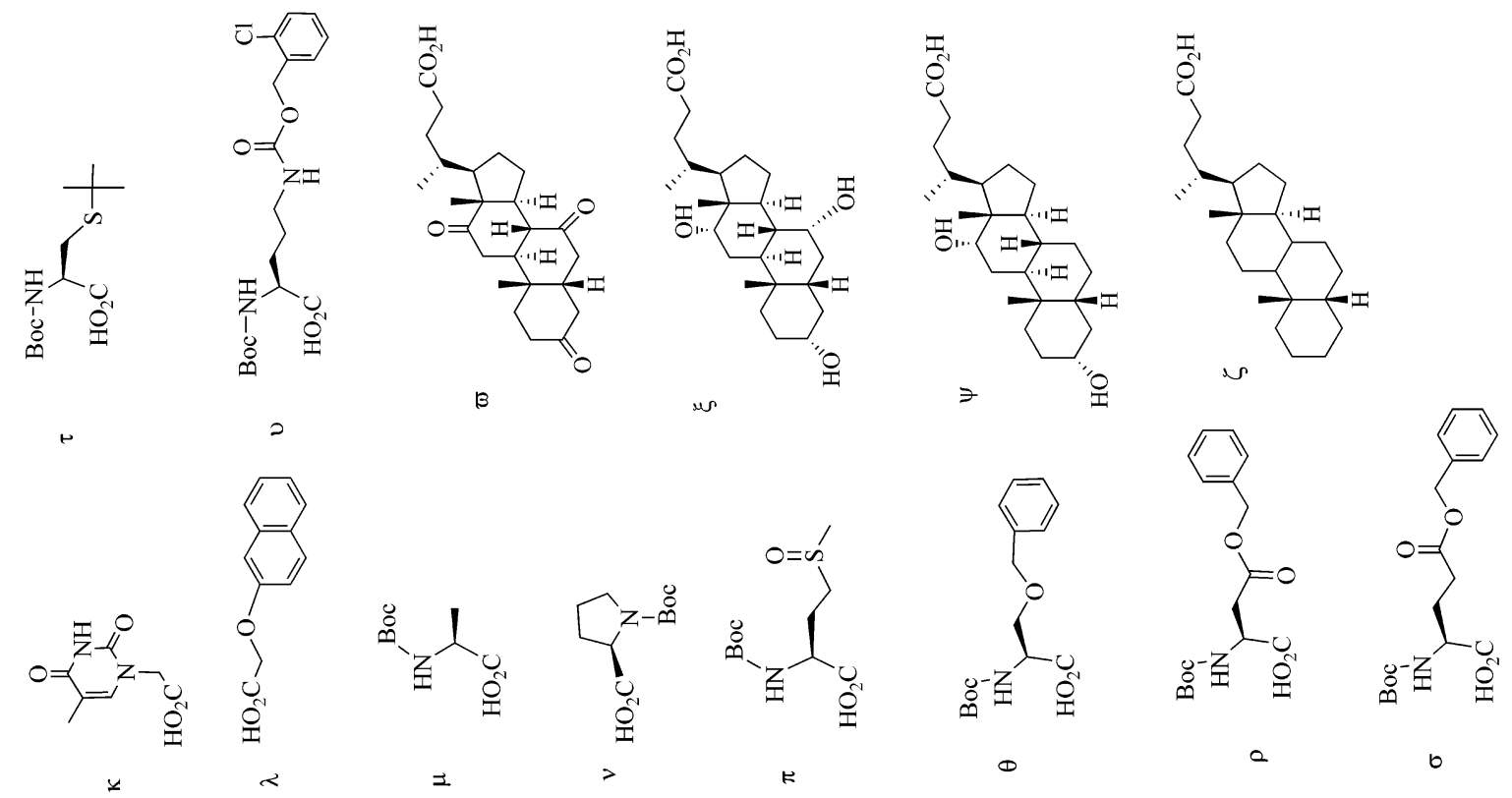

(1)

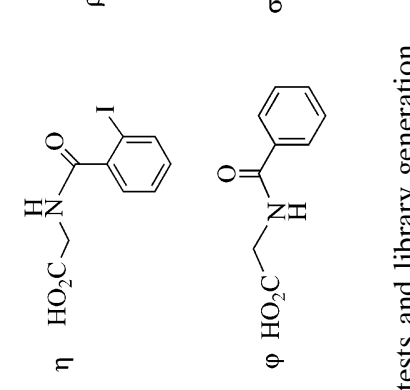

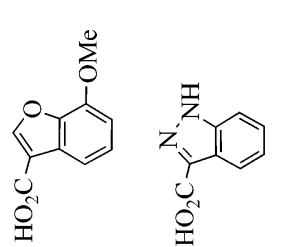

$=>$
8

$3 x$

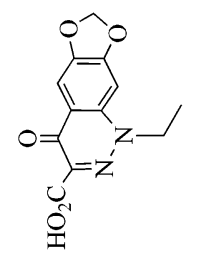

$>$

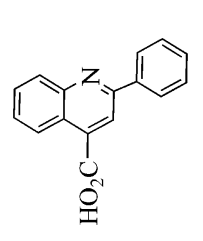

N
(1)

$\gamma \quad 0$

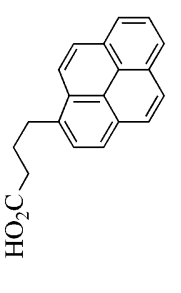

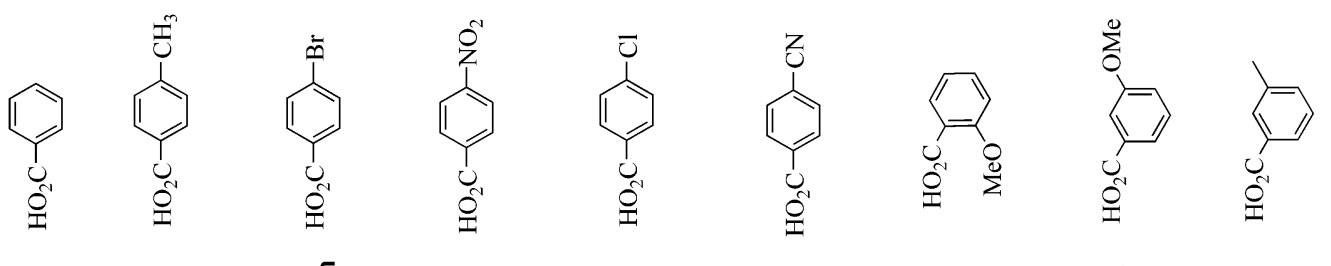
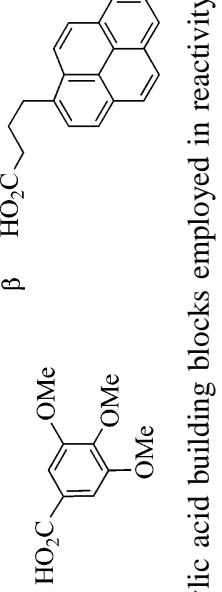

0
0
0
$\Xi$
0
0
00
0
0
0
0
0
0
0

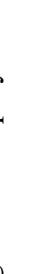

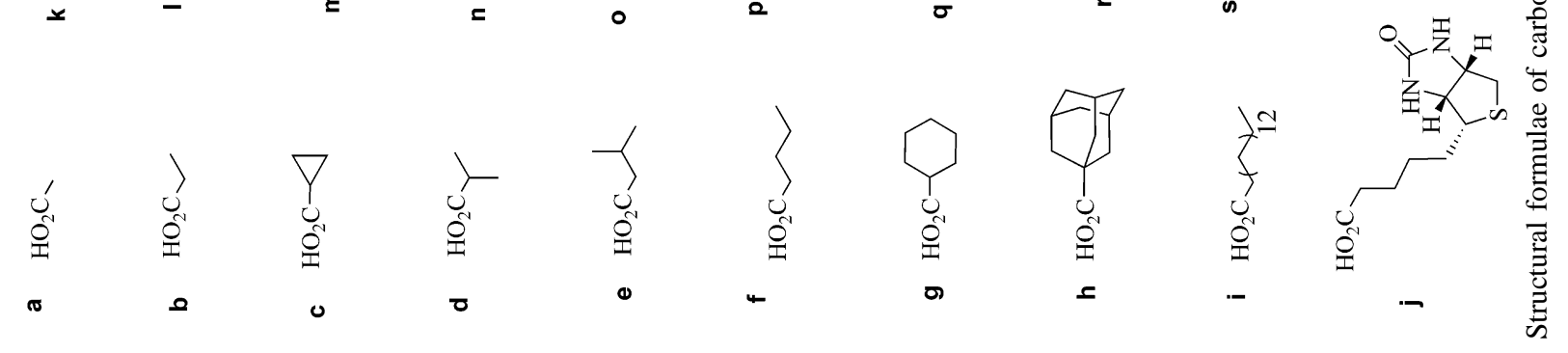



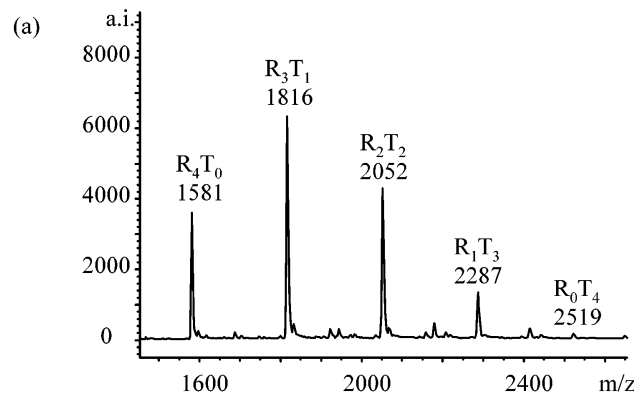

(b)

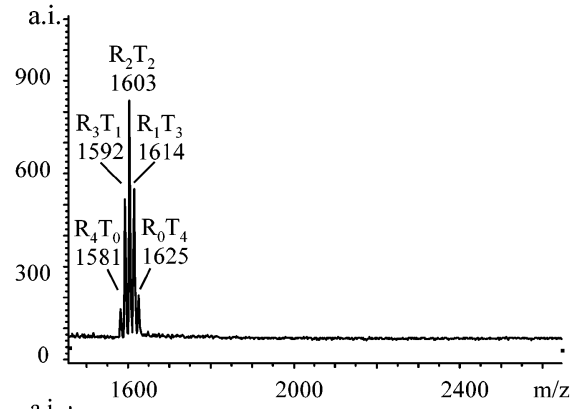

(c)

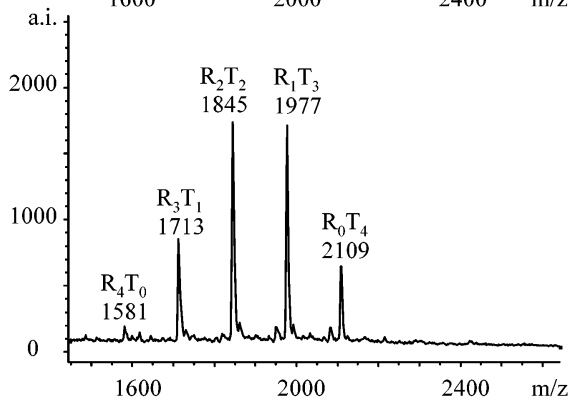

Figure 7. MALDI-TOF mass spectra of products formed in experiments following the format of assay 1 . Porphyrin libraries of general structure chemset 3 formed with Ac-Leu-OH as reference acid $\left(\mathrm{R}-\mathrm{CO}_{2} \mathrm{H}\right)$ and (a) cholic acid $(\xi),(\mathrm{b})$ thymine acetic acid $(\kappa)$, and $(\mathrm{c})$ iodohippuric acid $(\eta)$ as test acids $\left(\mathrm{T}-\mathrm{CO}_{2} \mathrm{H}\right)$.

1. Alternatively, they may more substantially influence the desorption/ionization properties of the respective oligonucleotides.

A second test was performed with reactivity adjusted mixtures and a protected and solid-phase-bound coupling partner. This was peptide 10 (Scheme 4), consisting of an SPKK motif ${ }^{23}$ with a C-terminal glycine residue. The peptide had been assembled on glycine-bearing Wang resin 11 using the Fmoc protocol. Mixed coupling reactions with a number (a)

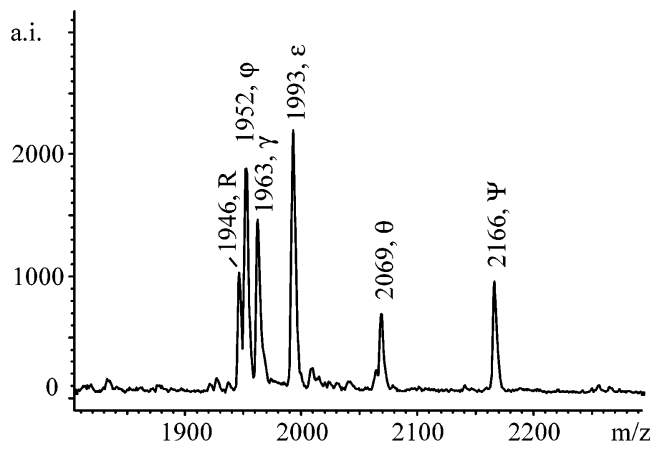

(b)

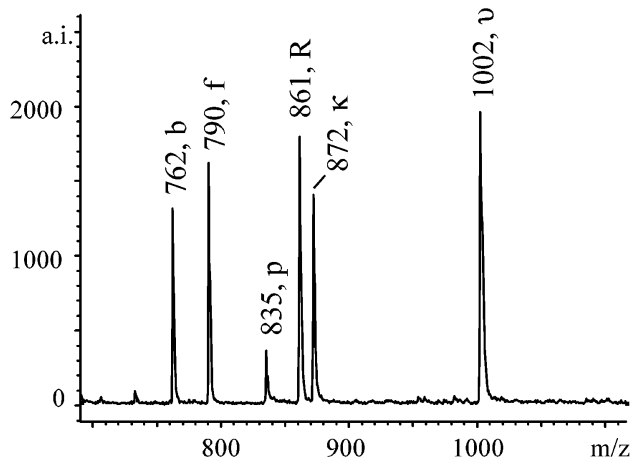

Figure 8. Representative MALDI-TOF mass spectra of (a) oligonucleotide libraries (chemset 5) and (b) peptide libraries (chemset 6) generated in couplings with reactivity-adjusted building block mixtures. The chemsets are library 7 for (a) and library 6 for (b)

of reactivity-adjusted coupling mixtures followed by deprotection with TFA and TIPS scavenger produced libraries of general structure chemset 6 . A MALDI-TOF mass spectrum of such a library (library 6) is shown in Figure 8b, and results from peak integrations from all libraries prepared are given in the penultimate column of Table 2 . Interestingly, there were not only more failures, where the desired product did not form detectably, but some compounds that were overrepresented in the spectra of the oligonucleotides were underrepresented in the peptide libraries and vice versa.

This led us to scrutinize the effect of the carboxylic acid residues on the desorption/ionization yield for different analytes in the MALDI-TOF mass spectrometer. An assay was developed that can produce relative reactivity values

\section{Scheme 3}
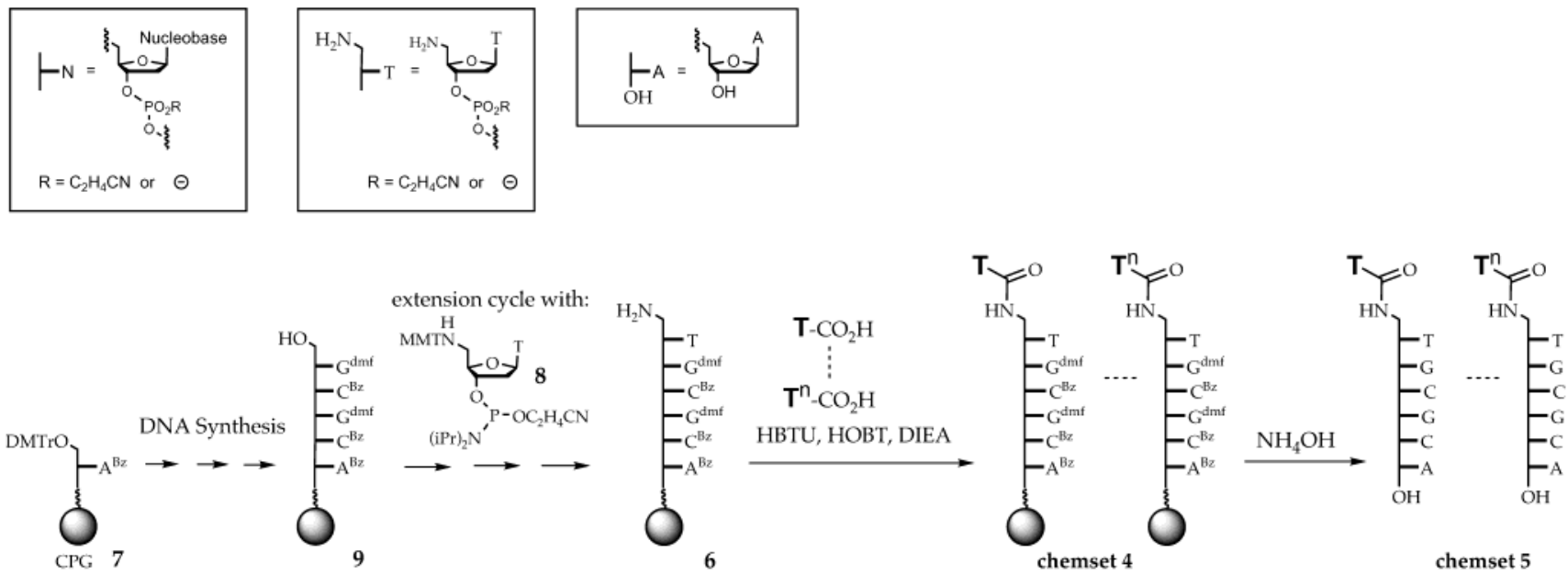

chemset 4

chemset 5 
Table 2. Relative Reactivity ( $r$ ) of Carboxylic Acids Determined in Competitive Coupling Assays with Ac-Leu-OH as Reference Acid, and Incorporation Results from Multicomponent Mixed Coupling Reactions Producing DNA Libraries Chemset 5 and Peptide Libraries Chemset 6

\begin{tabular}{|c|c|c|c|c|c|}
\hline \multirow{2}{*}{$\begin{array}{c}\text { library } \\
\text { T- } \mathrm{CO}_{2} \mathrm{H}\end{array}$} & \multirow[b]{2}{*}{ relative reactivity $(r)^{a}$} & \multirow[b]{2}{*}{$\mu \mathrm{mol}$ in $\operatorname{mix}^{b}$} & \multicolumn{2}{|c|}{ incorporation $^{c}$} & \multirow[b]{2}{*}{ rel. reactivity II $\left(r^{\prime}\right)^{d}$} \\
\hline & & & in chemset 5 & in chemset 6 & \\
\hline \multicolumn{6}{|l|}{ library 1} \\
\hline e & 0.27 & 12.4 & 0.92 & 0.97 & \\
\hline $\mathbf{k}$ & 0.28 & 12.0 & 0.87 & 0.84 & \\
\hline $\mathbf{S}$ & 0.13 & 25.8 & 1.41 & 1.30 & \\
\hline $\mathbf{h}$ & 0.11 & 30.5 & 1.25 & 0.65 & \\
\hline $\mathbf{t}$ & 0.21 & 16.0 & 0.55 & 1.23 & \\
\hline \multicolumn{6}{|l|}{ library 2} \\
\hline c & 0.29 & 21.3 & 1.68 & 1.71 & 0.22 \\
\hline l & 0.23 & 26.8 & 0.54 & 0.85 & 0.22 \\
\hline $\mathbf{r}$ & 0.36 & 17.1 & 0.93 & 1.32 & 0.16 \\
\hline$\delta$ & $0.43(1.02)^{e}$ & 14.3 & 0.16 & $-f$ & 1.74 \\
\hline $\boldsymbol{\beta}$ & 0.43 & 14.3 & 1.68 & 0.12 & 0.77 \\
\hline \multicolumn{6}{|l|}{ library 3} \\
\hline o & 0.43 & 19.3 & 1.16 & 2.19 & \\
\hline $\mathbf{x}$ & 0.43 & 19.3 & 1.64 & 2.03 & \\
\hline$\alpha$ & $0.43(1.07)^{e}$ & 19.3 & 0.38 & 0.16 & \\
\hline $\mathbf{w}$ & 0.54 & 15.4 & 0.27 & 0.63 & \\
\hline$\xi$ & 0.45 & 18.4 & 1.54 & 0.00 & \\
\hline \multicolumn{6}{|l|}{ library 4} \\
\hline d & 0.59 & 16.5 & 1.21 & 2.57 & \\
\hline g & $0.64(0.55)^{e}$ & 15.2 & 0.85 & 1.30 & \\
\hline q & 0.5 & 19.5 & 1.65 & 1.20 & \\
\hline $\mathrm{z}$ & 0.55 & 17.7 & 0.00 & 0.00 & \\
\hline$\omega$ & 0.46 & 21.2 & 1.29 & 0.00 & \\
\hline \multicolumn{6}{|l|}{ library 5} \\
\hline $\mathbf{v}$ & 0.83 & 15.2 & 0.22 & 0.00 & \\
\hline $\mathbf{u}$ & 0.82 & 15.3 & 0.58 & 0.37 & \\
\hline $\mathbf{m}$ & 0.69 & 18.2 & 1.63 & 1.02 & \\
\hline $\mathbf{j}$ & 0.66 & 19.1 & 2.31 & 2.57 & \\
\hline$\chi$ & $(0.64)^{g}$ & 19.7 & 0.26 & 1.04 & \\
\hline \multicolumn{6}{|l|}{ library 6} \\
\hline b & 0.95 & 15.9 & 2.24 & 0.84 & 0.63 \\
\hline f & 0.84 & 18.0 & 1.47 & 0.99 & 0.34 \\
\hline p & 0.96 & 15.8 & 0.18 & 0.19 & $0.88^{h}$ \\
\hline$\kappa$ & $1.18(0.87)^{e}$ & 17.4 & 0.37 & 0.96 & $1.57^{h}$ \\
\hline$v$ & 0.85 & 17.8 & 0.74 & 2.02 & \\
\hline \multicolumn{6}{|l|}{ library 7} \\
\hline$\varphi$ & 1.13 & 17.5 & 1.12 & & \\
\hline$\gamma$ & 1.3 & 15.2 & 1.04 & & \\
\hline$\epsilon$ & $(1.34)^{i}$ & 14.7 & 1.82 & & $(3.50)^{i}$ \\
\hline$\theta$ & 1.31 & 15.1 & 0.34 & & 1.49 \\
\hline$\psi$ & 1.11 & 17.8 & 0.68 & & 0.45 \\
\hline \multicolumn{6}{|l|}{ library 8} \\
\hline n & 1.42 & 16.1 & 0.02 & & \\
\hline$v$ & 1.45 & 15.8 & 1.20 & & 1.18 \\
\hline i & 1.42 & 16.1 & 0.75 & & $1.74^{h}$ \\
\hline$\eta$ & 1.51 & 15.1 & 2.03 & & $1.84^{h}$ \\
\hline \multicolumn{6}{|l|}{ library 9} \\
\hline$\mu$ & 1.82 & 15.4 & 1.46 & & 0.71 \\
\hline$\phi$ & 1.64 & 17.1 & 2.13 & & 0.98 \\
\hline$\sigma$ & 2.61 & 10.7 & 0.26 & & 2.26 \\
\hline $\mathbf{y}$ & 1.79 & 15.6 & 0.97 & & 2.11 \\
\hline$\tau$ & 2.12 & 13.2 & 0.18 & & 1.68 \\
\hline library 10 & & & & & \\
\hline $\mathbf{a}$ & 0.92 & $6.4^{j}$ & 0.90 & & \\
\hline$\ddot{\lambda}$ & 3.43 & 15.9 & 0.00 & & 2.73 \\
\hline$\pi$ & 2.35 & 23.2 & 1.23 & & 2.56 \\
\hline library 11 & & & & & \\
\hline$\phi$ & 1.64 & 13.8 & & 1.60 & 0.98 \\
\hline$\epsilon$ & $(1.34)^{i}$ & 16.9 & & 1.03 & $(3.50)^{i}$ \\
\hline$v$ & 1.45 & 15.6 & & 1.03 & 1.18 \\
\hline $\mathbf{i}$ & 1.42 & 16.0 & & 0.23 & $1.74^{h}$ \\
\hline$\eta$ & 1.51 & 15.0 & & 1.11 & $1.84^{h}$ \\
\hline
\end{tabular}

${ }^{a}$ Determined from statistically corrected relative peak intensities of neighboring peaks on the basis of results from assay $1 .{ }^{b}$ All mixed couplings were performed with $100 \mu \mathrm{mol}$ acids total; balance is Ac-Leu-OH. ${ }^{c}$ Relative peak integrals of expected products in the MALDITOF mass spectrum of the crude product. ${ }^{d}$ Determined from results obtained with assay $2 .{ }^{e}$ Mean value, obtained after averaging with a later redetermination, using assay $1 .{ }^{f}$ Compound not included in mixed coupling reaction with peptide scaffold. ${ }^{g}$ Strong side reactions observed (pattern of peaks with +16 mass units). ${ }^{h}$ Result from assay 2 in which the concentration ratio in the second experiment was $9: 1$, rather than 4:1. ${ }^{i}$ Substantial side reaction observed ( -139 mass units, loss of chlorobenzoyl group). ${ }^{j}$ The $r$ value obtained from a reactivity test without HOBT was used to calculate the amount to be used in this library. 


\section{Scheme 4}

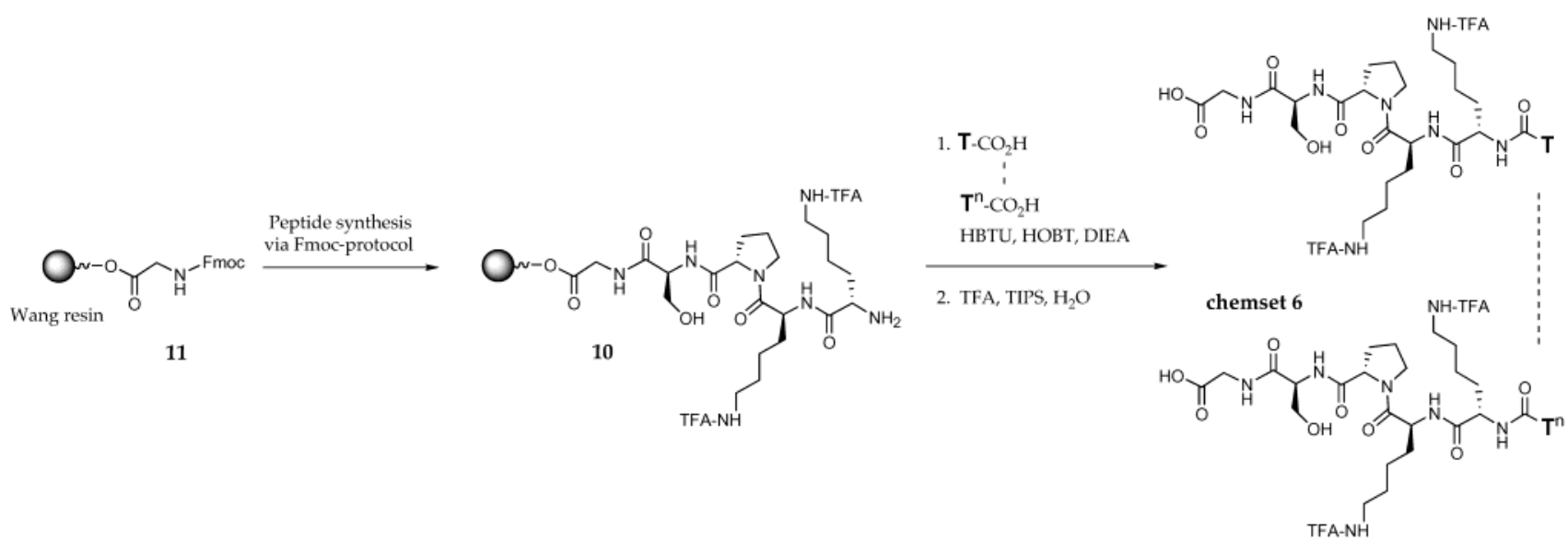

that are unbiased by the desorption/ionization differences or "flyability factor" of the individual porphyrins in chemset 3. The assay (assay 2) is schematically shown in Figure 9. The mathematical considerations that led to the development of this assay are given in the Supporting Information. Briefly, two reactions are performed at different ratios of test acid $\left(\mathrm{T}-\mathrm{CO}_{2} \mathrm{H}\right)$ and reference acid $\left(\mathrm{R}-\mathrm{CO}_{2} \mathrm{H}\right)$. Peak intensities of products are measured in the MALDI spectra of the two product mixtures with the aid of an internal standard. This allows one to eliminate the desorption/ionization factor that biases the reactivity values obtained from single spectra, since two equations (for the reaction at ratio $x$ and the reaction at ratio $x^{\prime}$ ) make it possible to determine both unknowns (relative reactivity and "flyability factor").

Representative spectra from an experiment performed according to the format of assay 2 with iodohippuric acid as test acid are shown in Figure 10. For every experiment, a $1-\mu \mathrm{L}$ aliquot of the reaction solution was mixed with $1 \mu \mathrm{L}$ of a solution containing $42 \mathrm{nmol}$ of tetrakis( $N$-acetylalanine)tetraphenylporphyrin 4 (Scheme 1) as internal standard, diluted with acetonitrile, and spotted with the 2,4,6-trihydroxyacetophenone/diammonium citrate matrix mixture. Further, 3 spectra per reaction were acquired. The relative reactivities obtained from a few exploratory assays ${ }^{24}$ are given in the rightmost column of Table 2. It can be discerned that there is no clear correlation between discrepancy in assay 1/assay 2 results and poor performance in mixed coupling reactions with either DNA or peptide.

It was suspected that factors other than the accuracy of the relative reactivities determined in the porphyrin-based assays was responsible for the drop-outs in the mixed coupling reactions. Specificially, in the solid support-based assays, the molecular weight or size of molecules was suspected to be a more predominant factor in determining the rate at which activated acids and amines encountered each other than in solution, since the pores of a support such as controlled-pore glass can be expected to have a sizeselecting effect. Accordingly, reactivity-adjusted mixtures were now prepared with more regard to grouping acids of similar molecular weight together. Still, the molecular weight of any member of a mixture was to be no closer than $10 \mathrm{Da}$ to any of the other members to avoid peak overlap in the MALDI spectra. In addition, some compounds that had proven unreactive in the assays whose results are presented in Table 2 were omitted. The results of the mixed couplings with these size-adjusted mixtures (libraries 12-20) are compiled in Table 3. There was only a single acid among the 31 compounds tested that did not give a detectable product signal in the libraries generated. Furthermore, there were only three acids whose products gave MALDI signal intensities not within a factor of 3 from the average peak height in the library. This factor-of-3 threshold was set as a criterion for usefulness in spectrometrically monitored selection assays (SMOSE). ${ }^{18}$ Accordingly, $>90 \%$ of all modified oligonucleotides generated with the size-adjusted mixtures could have been monitored well in SMOSE assays.

To carry this approach one step further, coupling reactions producing chemsets 5 were performed with reactivityadjusted mixtures containing acids from the same class of compounds only. The classes tested ranged from aliphatic acids to amino acids and included bile acids and structurally diverse acetic acid derivatives (Table 4). The differences in reactivity between the individual components in each mixture varied quite substantially, as reflected by differences in concentration in the reactivity-adjusted mixtures of up to 8 -fold. Still, the results from the mixed couplings with immobilized amino-terminal oligonucleotides (last column in Table 4) were encouraging. No complete drop-out was found, and all peak intensities were within a factor of 3 from the average peak intensity, making all chemsets (libraries 21-26) fully usable in SMOSE assays.

Two more factors that might affect the results of mixed coupling reactions were evaluated. One was the size of the mixtures, and the other was the activation method for the acids. A large reactivity-adjusted mixture, containing 21 acids $(\mathbf{a}, \mathbf{b}, \mathbf{c}, \mathbf{f}, \mathbf{g}, \mathbf{q}, \kappa, \mathbf{u}, \boldsymbol{\lambda}, \boldsymbol{v}, \epsilon, \phi, \boldsymbol{\alpha}, \boldsymbol{\pi}, \boldsymbol{\tau}, \boldsymbol{\beta}, \boldsymbol{\theta}, \boldsymbol{\eta}, \boldsymbol{\chi}, \boldsymbol{\xi}$, and Ac-Leu-OH), was prepared, activated in situ as before, and coupled with 6 to generate a larger library of general structure chemset 5. The MALDI spectrum of this library is shown in Figure S1 (Supporting Information). Though all products could be detected, five of the products gave MALDI peaks too small to be within the SMOSE cutoff of a factor 3 of the average peak height.

Last, a small collection of building blocks that did not require activation through the potentially biasing multistep process induced by HBTU/HOBT were tested. These are 

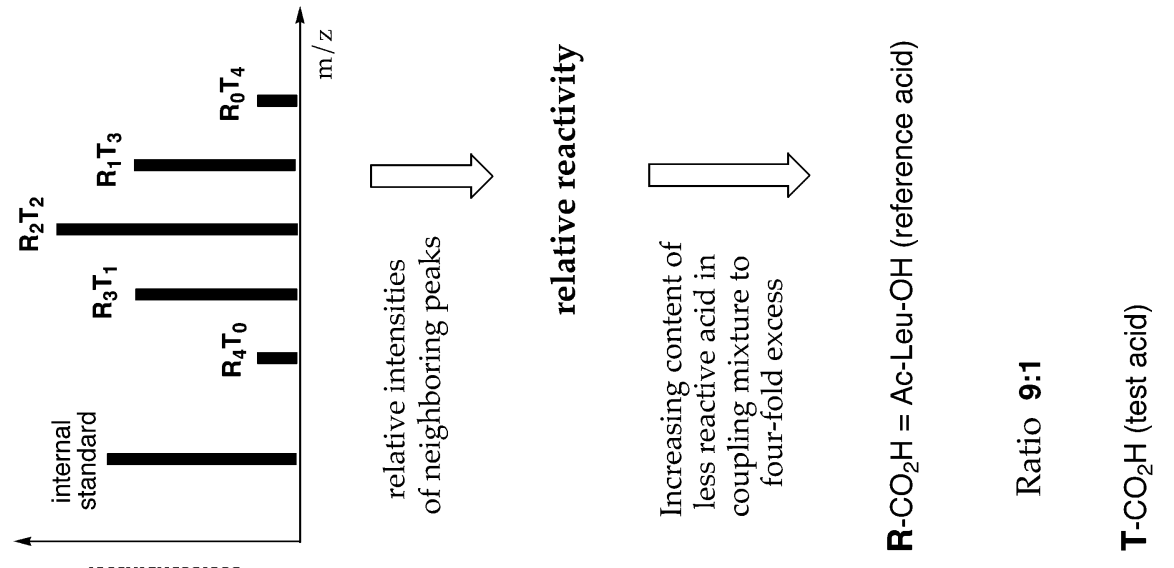

บотұехұนววนоว

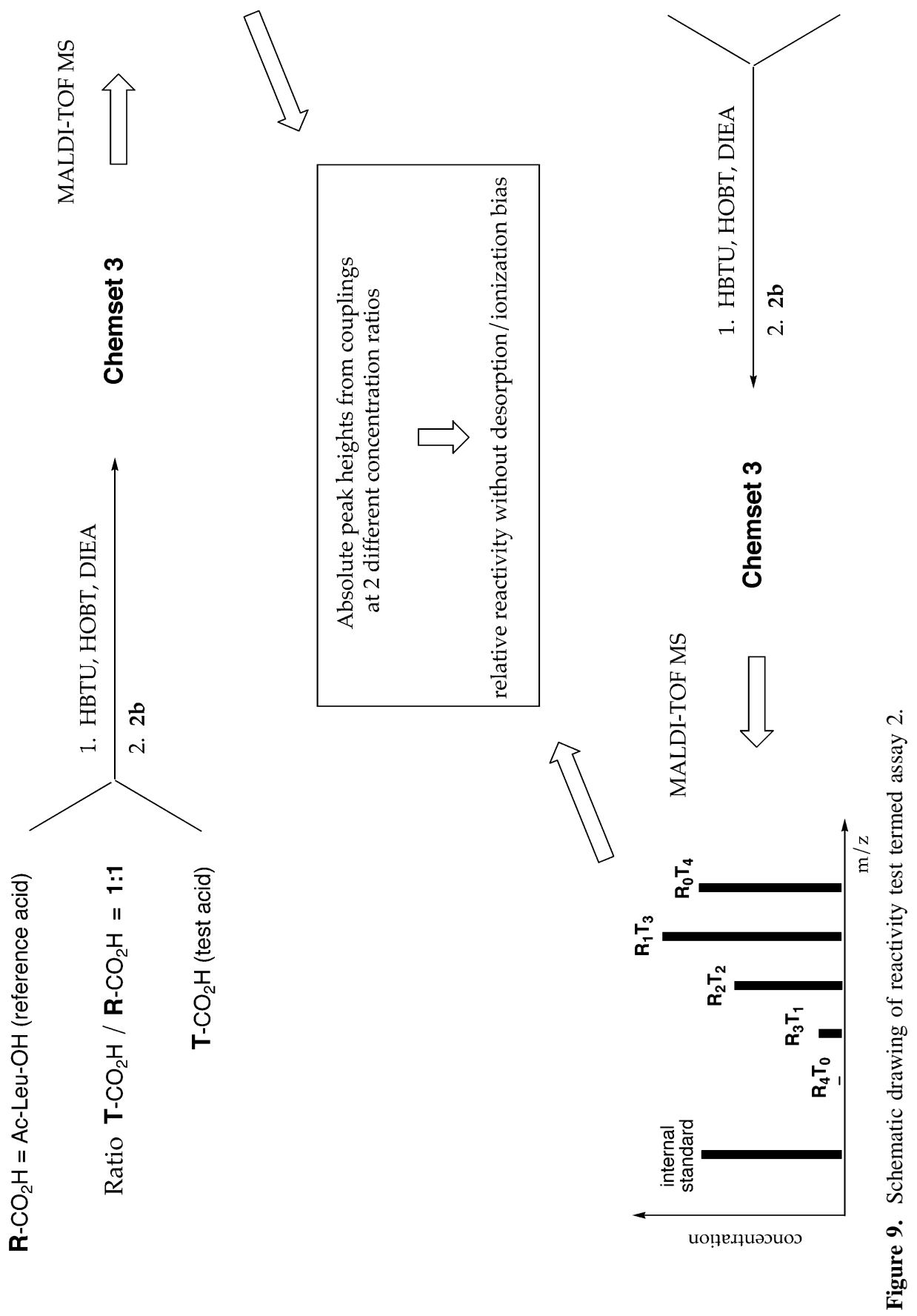



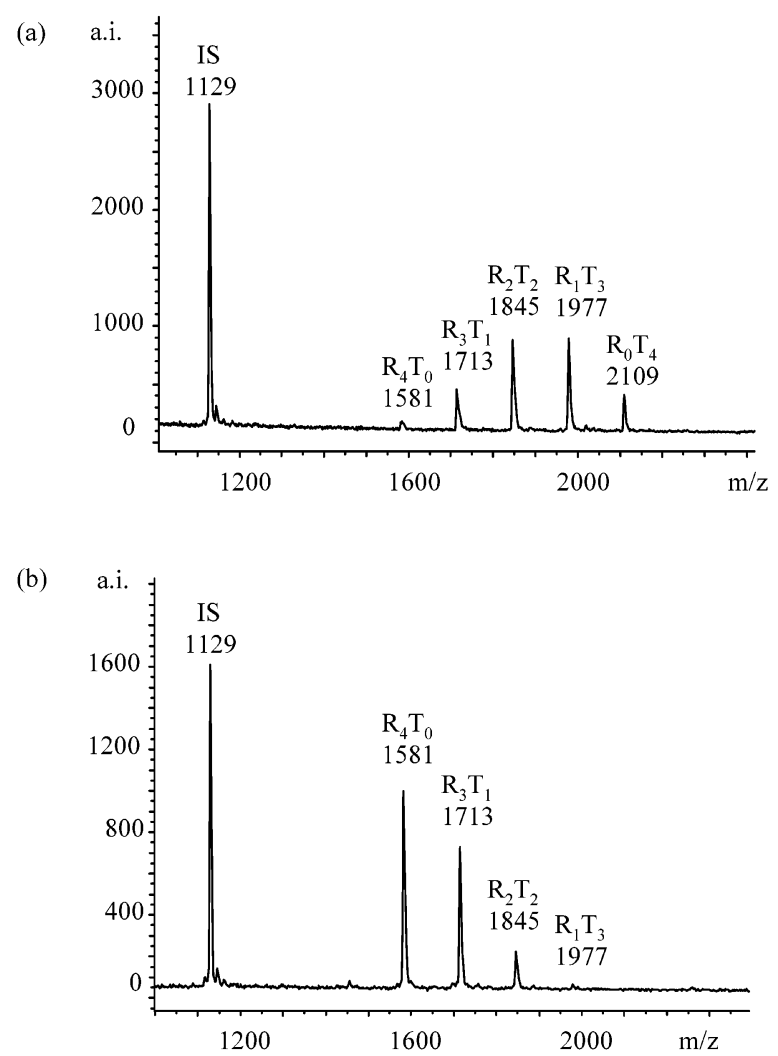

Figure 10. Representative MALDI-TOF mass spectra of porphyrin products of general structure chemset 3 generated in reactivity tests following the format of assay 2 with Ac-Leu-OH as reference acid $\left(\mathrm{R}-\mathrm{CO}_{2} \mathrm{H}\right)$ and iodohippuric acid $(\boldsymbol{\eta})$ as test acid $\left(\mathrm{T}-\mathrm{CO}_{2} \mathrm{H}\right)$. (a) Coupling at a molar ratio of 1:1 of the two acids and (b) coupling at a molar ratio of $\mathrm{R}-\mathrm{CO}_{2} \mathrm{H}$ to $\mathrm{T}-\mathrm{CO}_{2} \mathrm{H}, 9: 1$.

shown in Figure 11. Some structural diversity among these $\mathrm{N}$-hydroxysuccinimide derivatives was ensured by including sterically demanding compounds, such as valine derivative $\boldsymbol{\Omega}$; non-amino acids, such as $\mathbf{M}$ and $\boldsymbol{\Sigma}$, and electronically activated carbonate $\vartheta$. All building blocks are commercially available. Reactivity tests following format assay 1 were performed in THF at $50{ }^{\circ} \mathrm{C}$ for $16 \mathrm{~h}$ using the NHS ester of Ac-Leu-OH as reference compound. Two reactivity-adjusted mixtures were prepared on the basis of the $r$ values obtained and employed in mixed couplings to generate oligonucleotide libraries 27 and 28 (Table 5). With the exception of building block $\mathbf{M}$, the residue mass of which was too close to that of reference compound Ac-Leu-NHS to allow unambiguous analysis of assay 1, all building blocks coupled well, with peak intensities within a factor of 2 in the MALDI spectra of the libraries. Particularly for library 27 , this was encouraging, since the reactivity differences made concentration differences of up to 35 -fold necessary in the reactivityadjusted mixture.

\section{Discussion}

From these results, three factors emerge that improve the performance of reactivity-adjusted building block mixtures in couplings generating libraries of modified oligonucleotides. These are (i) the molecular weight difference between the building blocks employed in one mixture; (ii) the structural similarity of the core structure of the building blocks; and (iii) the activation chemistry, with preactivated
Table 3. Incorporation Results from Multicomponent Mixed Coupling Reactions Producing Libraries of General Structure Chemset 5 with Acids of Similar Molecular Weight Being Coupled Together

\begin{tabular}{|c|c|c|c|}
\hline $\begin{array}{l}\text { library } \\
\mathrm{T}-\mathrm{CO}_{2} \mathrm{H}\end{array}$ & MW & $\begin{array}{c}\mu \mathrm{mol} \\
\text { in } \text { mix }^{a}\end{array}$ & $\begin{array}{l}\text { incorporation } \\
\text { in chemset } 5^{b}\end{array}$ \\
\hline \multicolumn{4}{|l|}{ library 12} \\
\hline S & 136 & 43.6 & 1.49 \\
\hline d & 88 & 9.6 & 0.79 \\
\hline e & 102 & 22.0 & 0.69 \\
\hline $\mathbf{k}$ & 122 & 20.2 & 1.03 \\
\hline \multicolumn{4}{|l|}{ library 13} \\
\hline c & 86 & 36.9 & 1.30 \\
\hline g & 128 & 16.7 & 0.62 \\
\hline f & 102 & 12.7 & 0.84 \\
\hline b & 74 & 11.3 & 1.06 \\
\hline $\mathbf{a}$ & 60 & 11.6 & 1.19 \\
\hline \multicolumn{4}{|l|}{ library 14} \\
\hline h & 194 & 37.4 & 1.87 \\
\hline 1 & 136 & 17.9 & 0.64 \\
\hline $\mathbf{t}$ & 212 & 19.6 & 0.99 \\
\hline $\mathbf{r}$ & 152 & 11.4 & 1.32 \\
\hline $\mathbf{x}$ & 231 & 9.6 & 0.17 \\
\hline \multicolumn{4}{|l|}{ library 15} \\
\hline$\alpha$ & 242 & 24.5 & 1.17 \\
\hline $\mathbf{q}$ & 152 & 21.0 & 2.85 \\
\hline $\mathbf{m}$ & 201 & 15.2 & 0.44 \\
\hline $\mathbf{u}$ & 192 & 12.8 & 0.00 \\
\hline$\kappa$ & 184 & 15.9 & 0.54 \\
\hline \multicolumn{4}{|l|}{ library 16} \\
\hline$\varphi$ & 179 & 22.4 & 1.05 \\
\hline$\gamma$ & 189 & 19.5 & 1.20 \\
\hline$v$ & 215 & 17.4 & 0.45 \\
\hline$\phi$ & 229 & 15.4 & 1.30 \\
\hline \multicolumn{4}{|l|}{ library 17} \\
\hline$\xi$ & 408 & 49.3 & 1.19 \\
\hline$\tau$ & 277 & 10.4 & 0.45 \\
\hline $\boldsymbol{\mu}$ & 189 & 11.7 & 1.48 \\
\hline$\lambda$ & 202 & 6.5 & 0.88 \\
\hline \multicolumn{4}{|l|}{ library 18} \\
\hline $\boldsymbol{\beta}$ & 288 & 27.1 & 1.68 \\
\hline $\mathbf{j}$ & 244 & 17.7 & 1.18 \\
\hline$\chi$ & 316 & 18.2 & 0.24 \\
\hline$\omega$ & 402 & 25.4 & 0.90 \\
\hline \multicolumn{4}{|l|}{ library 19} \\
\hline$v$ & 415 & 17.5 & 0.94 \\
\hline$\psi$ & 392 & 16.3 & 0.63 \\
\hline $\boldsymbol{\theta}$ & 295 & 11.2 & 0.99 \\
\hline$\epsilon$ & 357 & 18.6 & 1.80 \\
\hline $\mathbf{y}$ & 262 & 10.1 & 0.64 \\
\hline \multicolumn{4}{|l|}{ library 20} \\
\hline$\eta$ & 305 & 22.9 & 2.57 \\
\hline$\dot{\pi}$ & 265 & 14.8 & 0.60 \\
\hline i & 256 & 14.5 & 1.16 \\
\hline $\boldsymbol{\sigma}$ & 337 & 10.9 & 0.66 \\
\hline
\end{tabular}

${ }^{a}$ All mixed couplings were performed with $100 \mu \mathrm{mol}$ acids total; balance is Ac-Leu-OH. ${ }^{b}$ Relative peak integrals of expected products in the MALDI-TOF mass spectrum of the crude product.

building blocks apparently performing better than building block mixtures activated with a (slightly substoichiometric) amount of HBTU/HOBT. Perhaps not surprisingly, the more diverse the set of building blocks (in terms of the first two factors), the more challenging the generation of equireactive mixture. However, our results do suggest that even mixtures of completely unrelated compounds grouped only by relative reactivity, such as those employed for the libraries presented 
Table 4. Incorporation Results from Multicomponent Mixed Coupling Reactions Producing Libraries of General Structure Chemset 5 with Acids of Similar Chemical Structure Being Coupled Together

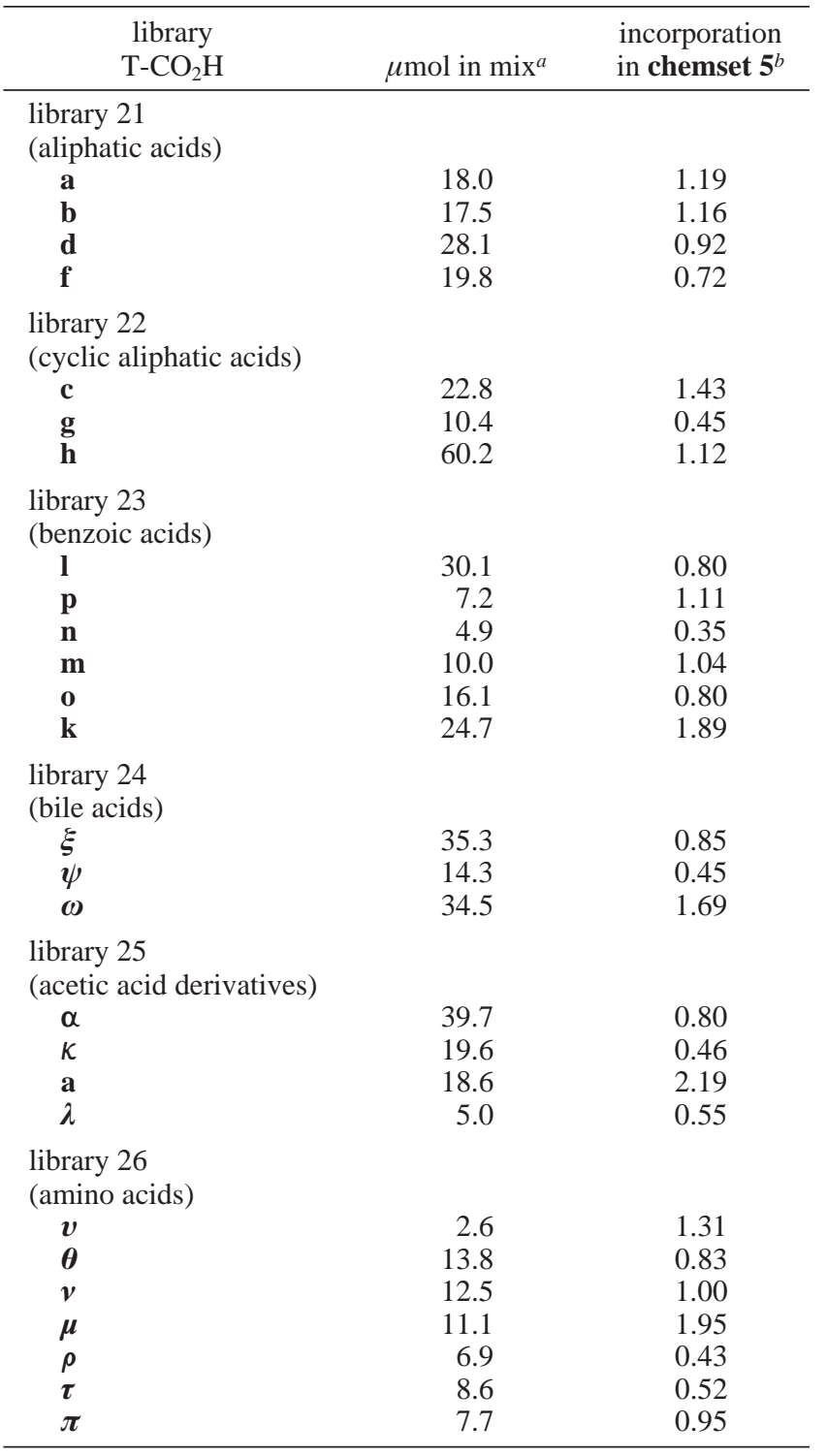

${ }^{a}$ All mixed couplings were performed with $100 \mu$ mol acids total; balance is Ac-Leu-OH. ${ }^{b}$ Relative peak integrals of expected products in the MALDI-TOF mass spectrum of the crude product.

in Table 2, can give over $85 \%$ successful incorporation when reactivity-tested first.

If less complex activation chemistries were used, the number of drop outs in the libraries formed may be reduced. Currently, compounds may be losing out in the competition for the activation agent or may be converted to mixed anhydrides when the most reactive (and thus, readily activated) compound reacts with leftover carboxylate of the least reactive building block. However, the activation with uronium salts is convenient and ensures high reactivity and was therefore not abandoned, despite the additional variables introduced.

The methodology involving reactivity tests prior to employing building blocks in mixed couplings, in itself, proved beneficial in our case, as preparation of individual modified oligonucleotide derivatives, their purification, and<smiles>CC(C)C[C@H](NC(=O)O)C(=O)ON1C(=O)CCC1=O</smiles><smiles>O=C(OCc1ccccc1Cl)ON1C(=O)CCC1=O</smiles><smiles>CC(C)[C@H](NC(=O)OC(C)(C)C)C(=O)ON1C(=O)CCC1=O</smiles><smiles>[M]C1CCC(=O)N1OC(=O)CCc1ccc(O)cc1</smiles><smiles>CSCC[C@H](NC(=O)OC(C)(C)C)C(=O)ON1C(=O)CCC1=O</smiles><smiles>CC(C)(C)OC(=O)NCCCC[C@H](NC(=O)OC(C)(C)C)C(=O)ON1C(=O)CCC1=O</smiles><smiles>CC(C)(C)OC(=O)N[C@@H](Cc1ccccc1)C(=O)ON1C(=O)CCC1=O</smiles>

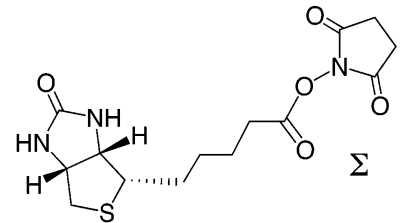

Figure 11. Structural formulae of preactivated building blocks employed for reactivity assays and library generation (compare to Table 5).

Table 5. Incorporation Results from Multicomponent Mixed Coupling Reactions Producing Libraries of General Structure Chemset 5 with $N$-Hydroxysuccinimide Esters/Carbonate as Activated Building Blocks

\begin{tabular}{cccc}
\hline $\begin{array}{c}\text { library } \\
\text { T-CO-OSu }\end{array}$ & $\begin{array}{c}\text { relative } \\
\text { reactivity }(r)^{a}\end{array}$ & $\begin{array}{c}\mu \text { mo } \\
\text { in mix }\end{array}$ & $\begin{array}{c}\text { incorporation } \\
\text { in chemset } \mathbf{5}^{c}\end{array}$ \\
\hline $\begin{array}{c}\text { library 27 } \\
\mathbf{\Omega}\end{array}$ & 0.05 & 89.8 & 1.08 \\
$\boldsymbol{\Delta}$ & 1.44 & 3.1 & 0.92 \\
$\mathbf{\Xi}$ & 1.73 & 2.6 & 1.00 \\
library 28 & & & \\
$\boldsymbol{\vartheta}$ & 3.78 & 37.7 & 0.95 \\
$\mathbf{M}$ & $(0.21)^{d}$ & 30.5 & 1.69 \\
$\mathbf{N}$ & 0.39 & 16.4 & 0.49 \\
$\mathbf{\Sigma}$ & 0.17 & 37.7 & 0.86 \\
\hline
\end{tabular}

${ }^{a}$ Determined from statistically corrected relative peak intensities of neighboring peaks obtained from assay 1 with Ac-Leu-NHS as reference compound. ${ }^{b}$ All mixed couplings were performed with $100 \mu \mathrm{mol}$ building blocks total; balance is Ac-Leu-OSu. ${ }^{c}$ Relative peak integrals of expected products in the MALDI-TOF mass spectrum of the crude product. ${ }^{d}$ Result of reactivity assay questionable due to too close a mass to Ac-Leu, causing peak overlap.

individual testing is considerably more laborious than mixed couplings followed by SMOSE assays with the crudes. ${ }^{22}$ Reactivity-adjusted mixtures, such as those presented in Tables 3-5 are now routinely used in these laboratories and have produced SMOSE-compatible libraries for other core molecules. ${ }^{25}$ On the basis of the available data, it appears that the relative rates of coupling different building blocks are roughly independent of the solid support-bound amine, in agreement with the results of others for amino acids and 
swellable supports. ${ }^{4}$ The number of reliable equireactive mixtures could be increased rapidly if the reactivity tests were to be automated. The current protocol starts with the generation of a building block stock solution in DMF, which is used in the reactivity test and all subsequent couplings, and thus employs almost exclusively liquids. Liquid handling, including MALDI sample preparation, can be readily automated. The same is true for the acquisition of MALDI spectra and data analysis. Maybe reactivity tests of building blocks with different forms of activation ${ }^{26}$ can also be accelerated by such automated tests. Expanding the set of equireactive mixtures beyond amino acid building blocks ${ }^{4}$ may revive the interest in mixed couplings as the simplest approach for generating diversity in untagged libraries, ${ }^{27,28}$ including those that are so large as to require recursive deconvolution. ${ }^{29}$

Some reactivities determined were quite unexpected and may, therefore, be of interest to the chemical community beyond the practical application of generating combinatorial libraries more efficiently. Why, for example, is naphthoxyacetic acid $(\lambda)$ more reactive (by a factor of 7 ) than pentafluorophenoxyacetic acid $(\boldsymbol{\alpha})$, when the latter is electronically more activated and sterically no more demanding? Rapid reactivity tests may allow the generation of reactivity databases with predictive power that may eventually approach that of the available linear free enthalpy relationships. Further, the approach to obtaining reactivity data corrected for the desorption/ionization factor that underlies assay 2 may be useful in other contexts than the present one. Using rapid assays of the general format assay 2, one may determine the effect of structural modifications on the yield of MALDI signals ("flyability factors", $F_{\mathrm{n}}$, Supporting Information) from relative peak intensities, without having to invoke more laborious calibration experiments. Even for repetitive polyanions, such as DNA, the effect of structure (i.e., base composition) on the MALDI signal can be substantial. ${ }^{30}$ Rapid assays that determine flyability of analytes may advance our understanding of desorption and ionization processes. ${ }^{11,31}$

Finally, some of the compounds prepared could be interesting in themselves. Terminally capped oligonucleotides can have increased affinity for target strands. ${ }^{32}$ Porphyrins are known to be well-suited for photosensitization of tumors ${ }^{33}$ and tetraphenylporphyrins and their chlorin derivatives are particularly promising candidates, the chemistry and photophysics of which continue to be explored. ${ }^{34}$ One such tetraphenylchlorin (FOSCAN, temporfin) was recently approved for the treatment of head and neck cancer in the European Union. ${ }^{35}$ The combinatorial synthesis of porphyrin libraries is still challenging, ${ }^{36}$ and reactivity-adjusted building block mixtures may help to generate porphyrin libraries to be tested as nucleic acid ligands, ${ }^{37}$ photosensitizers, sensors, designed materials, or catalysts. ${ }^{38}$

\section{Experimental Section}

General. The following solvents were of the best commercial quality and used without further purification: DMF, TFA (Fluka, Taufenkirchen, Germany), acetonitrile, and $\mathrm{MeOH}$ (Acros, Geel, Belgium). The following chemicals were also used as received: aqueous ammonia (ammonium hydroxide) and diisopropylethylamine (DIEA) (both Fluka); propionic acid, acetic acid, and tri-iso-propylsilane (Acros, Geel, Belgium); Fmoc-Gly-Wang resin (NovaBiochem, Läufelfingen, Switzerland); 2-(1H-benzotriazole-1-yl)-1,1,3,3tetramethyluronium hexafluorophosphate (HBTU), and hydroxybenzotriazole monohydrate (HOBT) (Advanced ChemTech, Louisville, KY). Carboxylic acids tested were used as received from Fluka/Sigma/Aldrich (Taufenkirchen, Germany), Acros, Merck (Darmstadt, Germany), Bachem (Heidelberg, Germany), NovaBiochem, and Advanced ChemTech. The phosphoramidite building blocks for $\mathrm{dA}^{\mathrm{Bz}}, \mathrm{dC}^{\mathrm{Bz}}$, and $\mathrm{T}$ were from Proligo (Hamburg, Germany) and from Glen Research (Sterling, VA) for $\mathrm{dG}^{\mathrm{dmf}}$. MALDI-TOF mass spectra were acquired on a Bruker BIFLEX III mass spectrometer in linear mode at $19 \mathrm{kV}$ total acceleration voltage (IS 1), the "short" setting of the instrument for delayed extraction ${ }^{39}$ and a repetition rate for the laser shots of $2 \mathrm{~Hz}$. For porphyrin samples, delayed extraction voltage was $17.3 \mathrm{kV}$ (IS 2). Spectra of DNA and peptide samples were acquired in negative mode with a delayed extraction voltage of $17.15 \mathrm{kV}$ (IS 2). A mixture of 2,4,6-trihydroxy acetophenone ( $0.3 \mathrm{M}$ in $\mathrm{EtOH})$ and diammonium citrate $(0.1$ $\mathrm{M}$ in water) was used as the matrix and comatrix at a ratio of $2: 1(\mathrm{v} / \mathrm{v})$ in all cases. It is important to emphasize that the attenuation of the laser should be well below the desorption/ionization threshold, if reproducible, meaningful relative peak intensities are to be obtained. For the current instrument, the desorption/ionization threshold for porphyrins is at an attenuation setting of $\sim 40$, and spectra were acquired at attenuation settings of $30 \pm 3(\sim 60-70 \mu \mathrm{J} /$ shot $)$. Spectra were acquired at pressures $<1 \times 10^{-6} \mathrm{mbar}$ in the drift tube. Calculated masses are average masses, $\mathrm{m} / \mathrm{z}$ found are those for the pseudomolecular ions $\left([\mathrm{M}-\mathrm{H}]^{-}\right.$or $\left.[\mathrm{M}+\mathrm{H}]^{+}\right)$ detected as the maximum of the unresolved isotope pattern. The accuracy of mass determination with the external calibration used was approximately $\pm 0.1 \%$, that is, $\pm 2 \mathrm{Da}$ at $m / z, 2000$.

$\mathbf{5 , 1 0 , 1 5 , 2 0 - T e t r a k i s ( p - a m i n o p h e n y l ) p o r p h y r i n ~ ( 1 ) . ~}{ }^{17 a} 5$,$10,15,20$-Tetrakis ( $p$-nitrophenyl)porphyrin was prepared as described by Bettelheim et al., ${ }^{17 a}$ except that glacial acetic acid instead of propionic acid was used, in an average yield of $14 \%$. MALDI-TOFMS $m / z$ for $\mathrm{C}_{44} \mathrm{H}_{26} \mathrm{~N}_{8} \mathrm{O}_{8}[\mathrm{M}+\mathrm{H}]^{+}$: calcd, 793.2; found, 792.7. The tetranitroporphyrin was reduced to 5,10,15,20-tetrakis( $p$-aminophenyl)porphyrin (1) ${ }^{17 a}$ with $\mathrm{SnCl}_{2}$ and $\mathrm{HCl}$ using the conditions of Bookser and Bruice for the meta isomer, ${ }^{17 \mathrm{~b}}$ leading to $\mathbf{1}$ in an average yield of 59\% after chromatography and crystallization. MALDI-TOFMS $m / z$ for $\mathrm{C}_{44} \mathrm{H}_{34} \mathrm{~N}_{8}[\mathrm{M}+\mathrm{H}]^{+}$: calcd, 674.3; found, 673.7 .

$5,10,15,20$-Tetrakis[p-(No-(tert-butyloxycarbonyl)-Lalanylamino)phenyl]porphyrin (2). A mixture of Boc-AlaOH (226.4 mg, $1.20 \mathrm{mmol}$ ), HBTU (410.2 mg, $1.08 \mathrm{mmol}$, 0.9 equiv), and HOBT (183.8 mg, $1.20 \mathrm{mmol}, 1$ equiv) were dried at 0.1 Torr and dissolved in DMF $(8 \mathrm{~mL})$. After vortexing, DIEA (446 $\mu \mathrm{L}, 2.64 \mathrm{mmol}, 2.2$ equiv) was added, followed by vortexing. Tetraanilinoporphyrin $1(102.7 \mathrm{mg}$, $0.152 \mathrm{mmol}$ ) was added to the solution under stirring. After $1 \mathrm{~h}$, water $(30 \mathrm{~mL})$ was added, followed by the addition of $\mathrm{CH}_{2} \mathrm{Cl}_{2}(60 \mathrm{~mL})$. The organic phase was separated and 
washed with water $(2 \times 60 \mathrm{~mL})$, brine $(3 \times 70 \mathrm{~mL})$, and saturated $\mathrm{NaHCO}_{3}(3 \times 70 \mathrm{~mL})$. The organic phase was dried over $\mathrm{NaSO}_{4}$ and evaporated to dryness, and the residue was chromatographed twice on silica, first with $\mathrm{CH}_{2} \mathrm{Cl}_{2} / \mathrm{THF}$ (4: 1, v/v) and then with $\mathrm{CHCl}_{3} / \mathrm{MeOH} / \mathrm{H}_{2} \mathrm{O}$ (900:100:1, v/v). Product fractions were combined and evaporated to dryness, and the residue was recrystallized thermally from $\mathrm{CHCl}_{3} /$ $\mathrm{MeOH}\left(98: 2, \mathrm{v} / \mathrm{v}, 50{ }^{\circ} \mathrm{C}\right.$ to room temperature) $(10 \mathrm{~mL})$. Yield: $140.5 \mathrm{mg}(103.4 \mu \mathrm{mol}, 68 \%) .{ }^{1} \mathrm{H}$ NMR $(250 \mathrm{MHz}$, DMSO- $d_{6}$ ): $\delta-2.15$ (br s, 2H), $1.39(\mathrm{~d}, J=7.3 \mathrm{~Hz}$, overlapping), 1.44 (s, $48 \mathrm{H}$ with overlapping signal at 1.39 ppm), 4.25 (quin, $J=7.3 \mathrm{~Hz}, 4 \mathrm{H}), 7.22(\mathrm{~d}, J=7.3 \mathrm{~Hz}$, 4H), 8.10 (AA'BB' system, 16H), 8.87 (br s, 8H), 10.4 (br $\mathrm{s}, 4 \mathrm{H})$. UV/vis $(\mathrm{MeOH}) \lambda_{\max }\left(\epsilon\right.$ in $\left.\mathrm{M}^{-1} \mathrm{~cm}^{-1}\right) 417$ (235 000), 514 (21 000), 551 (18 000), 592 (14 000). MALDI-TOFMS for $m / z \mathrm{C}_{76} \mathrm{H}_{86} \mathrm{~N}_{12} \mathrm{O}_{12}[\mathrm{M}+\mathrm{H}]^{+}$: calcd, 1358.7; found, 1359.4.

Analogous coupling of Ac-Ala-OH to $\mathbf{1}$ produced 4. Analytical data for 4: ${ }^{1} \mathrm{H}$ NMR $\left(250 \mathrm{MHz}, \mathrm{DMSO}-d_{6}\right): \delta$ -2.93 (br s, 2H), 1.42 (d, $J=7.0 \mathrm{~Hz}, 12 \mathrm{H}), 1.93$ (s, 12H), $4.57(\operatorname{tr}, J=7.1 \mathrm{~Hz}, 4 \mathrm{H}), 8.10\left(\mathrm{AA}^{\prime} \mathrm{BB}^{\prime}\right.$ system, $\left.16 \mathrm{H}\right), 8.35$ (d, $J=7.2 \mathrm{~Hz}, 4 \mathrm{H}), 8.86$ (br s, $8 \mathrm{H}$ ), 10.49 (br s, 4H). MALDI-TOFMS for $m / z \mathrm{C}_{64} \mathrm{H}_{62} \mathrm{~N}_{12} \mathrm{O}_{8}[\mathrm{M}+\mathrm{H}]^{+}$: calcd, 1127.3; found, 1128.1.

$\mathbf{5 , 1 0 , 1 5 , 2 0 - T e t r a k i s}[p$-(N $\alpha$-L-alanylamino)phenyl $]$ porphyrin (2b). Boc-protected precursor $2(32.1 \mathrm{mg}, 23.64$ $\mu \mathrm{mol})$ was dissolved in $\mathrm{CH}_{2} \mathrm{Cl}_{2}(2 \mathrm{~mL})$ and was treated with TFA $(1.95 \mathrm{~mL})$, followed by addition of water $(500 \mu \mathrm{L})$ and vortexing. After $20 \mathrm{~min}$, the solution was dripped into diethyl ether $(\sim 20 \mathrm{~mL})$ followed by centrifugation. The supernatant was removed, and the precipitate was treated with fresh diethyl ether $(20 \mathrm{~mL})$, followed by centrifugation and removal of the supernatant. The remaining precipitate was dried at 0.1 Torr. Yield: $18.56 \mathrm{mg}(19.3 \mu \mathrm{mol}, 82 \%) .{ }^{1} \mathrm{H}$ NMR $\left(250 \mathrm{MHz}\right.$, DMSO- $\left.d_{6}\right): \delta-2.18(\mathrm{~s}, 2 \mathrm{H}), 1.61$ (d, $J=$ $6.9 \mathrm{~Hz}, 12 \mathrm{H}), 4.20$ (br t, 4H), $7.22(\mathrm{~d}, 1 \mathrm{H}), 8.14\left(\mathrm{AA}^{\prime} \mathrm{BB}^{\prime}\right.$ system, $16 \mathrm{H}), 8.34$ (br s, $8 \mathrm{H}), 8.86$ (br s, 4H). UV/vis $(\mathrm{MeOH}) \lambda_{\max }\left(\epsilon\right.$ in $\left.\mathrm{M}^{-1} \mathrm{~cm}^{-1}\right) 417$ (524 000), 515 (20 000), 552 (18 000), 591 (16 000). MALDI-TOFMS for $\mathrm{m} / \mathrm{z}$ $\mathrm{C}_{56} \mathrm{H}_{54} \mathrm{~N}_{12} \mathrm{O}_{4}[\mathrm{M}+\mathrm{H}]^{+}$: calcd, 958.4; found, 959.3.

Assay 1, Generating Chemset 3. Stock solutions of the carboxylic acids in DMF (0.13 $\mathrm{M}$ for each acid) were prepared after drying each acid at 0.1 Torr. Aliquots of the stock solutions of Ac-Leu-OH $\left(\mathrm{R}-\mathrm{CO}_{2} \mathrm{H}, 17.5 \mu \mathrm{mol}\right)$ and the test acid ( $\left.\mathrm{T}-\mathrm{CO}_{2} \mathrm{H}, 17.5 \mu \mathrm{mol}\right)$ in $\mathrm{DMF}(270 \mu \mathrm{L}$ total volume) were combined and treated with a freshly made solution of HBTU (12.6 mg, $33.3 \mu \mathrm{mol}, 0.95$ equiv) and HOBT (5.4 $\mathrm{mg}, 35 \mu \mathrm{mol}, 1$ equiv) in DMF (125 $\mu \mathrm{L})$, and the resulting mixture was vortexed. The activating reagents had also been dried at 0.1 Torr prior to being dissolved in DMF. Next, DIEA ( $13 \mu \mathrm{L}, 2.2$ equiv) was added, followed by vortexing. After $10 \mathrm{~min}, 1 \mu \mathrm{L}$ of a stock solution of tetrakis(alanylanilino)porphyrin 2b in DMF (containing $0.04 \mathrm{mg}$, $0.042 \mu \mathrm{mol}, 0.012$ equiv of the porphyrin) was added, followed by vortexing. ${ }^{40}$ After $60 \mathrm{~min}$, a sample of $1 \mu \mathrm{L}$ was treated with $\mathrm{CH}_{3} \mathrm{CN}(30 \mu \mathrm{L})$ in a separate polypropylene vessel. An aliquot of the resulting mixture $(1 \mu \mathrm{L})$ was spotted on a MALDI target plate, followed by drying at 0.1 Torr for $10 \mathrm{~min}$. A matrix mixture of THAP $(1.2 \mu \mathrm{L}$ of a saturated solution in EtOH) and diammonium citrate $(0.6 \mu \mathrm{L}$ of a 0.3 $\mathrm{M}$ solution in water) was spotted on top of the residue from the analyte deposition, followed by mixing via aspiration and extrusion of the matrix solution with a semiautomatic pipet and drying at ambient pressure. One MALDI-TOF mass spectrum was acquired under the standard conditions given in the General Section.

Analogous coupling of Ac-Leu-OH alone produced 5. Analytical data for 5: ${ }^{1} \mathrm{H}$ NMR $\left(250 \mathrm{MHz}, \mathrm{DMSO}-d_{6}\right): \delta$ -3.10 (br s, 2H), 0.91 (m, 24H), 1.1-1.6 ppm (m, 24H), $1.92(\mathrm{~d}, J=6.0 \mathrm{~Hz}, 12 \mathrm{H}), 4.39(\mathrm{~m}, 4 \mathrm{H}), 4.55(\mathrm{t}, J=6.8$ $\mathrm{Hz}, 4 \mathrm{H}), 8.08-8.22(\mathrm{~m}, 16 \mathrm{H}), 8.35(\mathrm{~d}, J=6.9 \mathrm{~Hz}, 4 \mathrm{H})$, 8.64 (d, $J=7.5 \mathrm{~Hz}, 4 \mathrm{H}), 8.87$ (br s, $8 \mathrm{H}), 10.21$ (br s, 4H). MALDI-TOFMS for $m / z \mathrm{C}_{88} \mathrm{H}_{106} \mathrm{~N}_{16} \mathrm{O}_{12}[\mathrm{M}+\mathrm{H}]^{+}$: calcd, 1579.9; found, 1581.1.

Assay 2, Generating Chemset 3. A mixture of two activated carboxylic acids $\left(\mathrm{R}-\mathrm{CO}_{2} \mathrm{H}\right.$ and $\left.\mathrm{T}-\mathrm{CO}_{2} \mathrm{H}\right)$ was generated as described for assay 1 . For the first of the two couplings, the concentration of the two acids was identical to that given for assay 1 .

For the second of the two coupling reactions, the concentration of the acids was adjusted such that $7 \mu \mathrm{mol}$ of the less reactive acid (as determined in the first of the two reactions) and $28 \mu \mathrm{mol}$ of the more reactive acid were present in the coupling mixture (4:1 regimen). Alternatively, the ratio in this second coupling was chosen to be $3.5 \mu \mathrm{mol}$ of the less reactive acid and $31.5 \mu \mathrm{mol}$ of the more reactive acid (9:1 regimen). After 60-min reaction time, an aliquot $(1 \mu \mathrm{L})$ was drawn from the reaction mixture, mixed with $1 \mu \mathrm{L}$ of a solution of internal standard 4 (containing $0.04 \mathrm{mg}, 42 \mathrm{nmol}$ ), and diluted with $25 \mu \mathrm{L}$ of acetonitrile, and $0.5 \mu \mathrm{L}$ of the resulting solution was subjected to MALDI-TOFMS analysis, as described above for assay 1, except that three MALDI spectra were acquired, and relative peak intensities (analyte/ internal standard) were averaged over the three spectra. Relative reactivities $\left(r^{\prime}\right)$ were calculated as described in the Supporting Information.

Data Analysis. MALDI-TOF mass spectra were analyzed using the XMASS software, version 5.0.2, provided with the mass spectrometer. Spectra with less than 1000 ions counts for the most prominent peak were discarded. Peaks with an intensity below $1 / 25$ of the most intense peak of the members of chemset 3 were excluded from the analysis. For assay 1, peaks were integrated using the macro $\mathrm{DAS}^{22}$ that is available free of charge from the authors' web page. DAS selects a mass region, expands the $y$ axis, performs two-point smoothing and five-point filtering, labels peaks of interest, integrates the spectrum using predetermined mass regions, and generates a report file. Integral values were then imported into a Microsoft Excel spreadsheet calculating the reactivity score as the average of the peak ratios corrected for the statistical factor. For assay 2, peak heights were measured either onscreen or on printouts of the spectra, and the values thus obtained were expressed as relative peak intensities (analyte divided by internal standard). The relative peak heights were entered into an Excel spreadsheet containing the appropriate functions, yielding the desired reactivity ratios as the average of $r$ values obtained for all peaks that met intensity criterion $(1 / 25$ of the most prominent peak in the pattern for chemset 
3) in the spectra from both experiments (equal and nonequal concentration of acids).

Chemset 5. Partially protected, controlled pore glassbound oligonucleotide T*GCGCA-cpg (6), where T* denotes a 5'-amino-5'-deoxythymidine residue, was synthesized on an ABI $380 \mathrm{~B}$ DNA synthesizer on a $3-\mu \mathrm{mol}$ scale as described previously. ${ }^{22}$ The monomethoxytrityl group on the 5 -terminus of the DNA was removed under standard deblocking conditions on the DNA synthesizer, followed by rinsing the controlled-pore glass with $\mathrm{CH}_{3} \mathrm{CN}(10 \mathrm{~mL})$ and drying at 0.1 Torr for $30 \mathrm{~min}$. The mixture of activated acids was prepared by mixing stock solutions $(0.13 \mathrm{M})$ of the acids at a ratio calculated from the relative reactivities determined in assay 1 or assay 2. Each mixture contained five test acids $\left(\mathrm{T}-\mathrm{CO}_{2} \mathrm{H}\right)$ and $\mathrm{Ac}-\mathrm{Leu}-\mathrm{OH}\left(\mathrm{R}-\mathrm{CO}_{2} \mathrm{H}\right)$. The reciprocal value of the relative reactivity value for all acids in one coupling mixture were added, and the sum was divided by 100 (for reactions with $100 \mu \mathrm{mol}$ acids total). The number thus obtained was multiplied by the reciprocal value of the relative reactivity of each acid to obtain the number of micromoles of this acid to be employed in the mixture. The required aliquot of the stock solution for each carboxylic acid was added to a polypropylene reaction vessel to give a mixture with $100 \mu \mathrm{mol}$ of acids total in $769 \mu \mathrm{L}$ of DMF total. Separately, HBTU (37.9 mg, $100 \mu \mathrm{mol}, 0.9$ equiv) and HOBT (15.3 mg, $100 \mu \mathrm{mol}, 1$ equiv) were dried at 0.1 Torr for $1 \mathrm{~h}$, followed by dissolving them in DMF $(200 \mu \mathrm{L})$ and addition to the mixture of carboxylic acids. The resulting mixture was treated with DIEA ( $40 \mu \mathrm{L}, 220 \mu \mathrm{mol}, 2.2$ equiv) and vortexed. After $10 \mathrm{~min}$, the $5^{\prime}$-deprotected DNA T*GCGCA-cpg $(6,3 \mathrm{mg}, \sim 0.1 \mu \mathrm{mol}$ loading) was added to the vessel, followed by vortexing. During the coupling reaction, the slurry was vortexed every $5 \mathrm{~min}$. After $60 \mathrm{~min}$, the supernatant was removed using a syringe. The solid support was rinsed with DMF $(2 \times 1.5 \mathrm{~mL})$ and $\mathrm{MeOH}(2$ $\times 1.5 \mathrm{~mL}$ ) and dried at 0.1 Torr. Concentrated aqueous ammonia (ammonium hydroxide, $1.5 \mathrm{~mL}$ ) was added to the support, followed by vortexing. After $16 \mathrm{~h}$ at room temperature, $\sim 1 \mu \mathrm{L}$ of the supernatant was placed on the MALDI target. Excess ammonia was allowed to evaporate, and the matrix and comatrix were spotted onto the target area of deposition, followed by drying and MALDI-TOFMS analysis.

Chemset 6. A sample of Fmoc-Gly-loaded Wang resin 11 (60 mg, $60 \mu \mathrm{mol}$ loaded peptide according to the manufacturer's analysis) was Fmoc-deprotected by four treatments with piperidine/DMF $(1: 4, \mathrm{v} / \mathrm{v}, 1.4 \mathrm{~mL})$ for $1-10$ min each. The resin was then rinsed with DMF $(20 \mathrm{~mL})$. A mixture of Fmoc-Ser-OH (39.9 mg, $104 \mu \mathrm{mol}, 1.7$ equiv), HOBT (13.6 mg, $89 \mu \mathrm{mol}, 1.5$ equiv), and HBTU (36.3 mg, $96 \mu \mathrm{mol}, 1.6$ equiv) was dissolved in DMF (300 $\mu \mathrm{L})$ with vortexing, and treated with DIEA (2.2 equiv, $24.5 \mu \mathrm{L})$, and the resulting mixture was vortexed again. The solution was added to the resin, and the reaction was allowed to proceed for $45 \mathrm{~min}$ with vortexing every $5 \mathrm{~min}$. At the end of the reaction, the support was rinsed with DMF $(3 \times 10 \mathrm{~mL})$. The coupling was repeated once. After the second coupling and washing, the resin was Fmoc-deprotected with piperidine/DMF as above. Subsequent couplings were performed analogously, except that Fmoc-Pro-OH (34.2 mg, $101 \mu \mathrm{mol})$ or Fmoc-Lys(TFA)-OH (47.8 mg, $103 \mu \mathrm{mol})$ was used. Prior to removal of the Fmoc group of the second Lys residue, the resin was rinsed with $\mathrm{DMF}(15 \mathrm{~mL}), \mathrm{MeOH}(15 \mathrm{~mL})$, and $\mathrm{CH}_{2} \mathrm{Cl}_{2}(20 \mathrm{~mL})$ and was dried at 0.1 Torr. An analytical sample $(1 \mathrm{mg})$ deprotected with a mixture of TFA $(45 \mu \mathrm{L})$, tri-iso-propylsilane (TIPS, $2.5 \mu \mathrm{L})$, and water $(2.5 \mu \mathrm{L})$ for $11 \mathrm{~h}$ gave MALDI-TOFMS $m / z$, for $\mathrm{C}_{41} \mathrm{H}_{49} \mathrm{~N}_{7} \mathrm{O}_{11} \mathrm{~F}_{6}([\mathrm{M}+$ $\mathrm{H}^{+}$): calcd, 929.3; found, 929.8. The Fmoc-group on the $\mathrm{N}$-terminal Lys residue was then removed with piperdine/ DMF as described above to produce $\mathbf{1 0}$, followed by washing with DMF $(3 \times 1.5 \mathrm{~mL})$ and drying at 0.1 Torr. A mixture of activated carboxylic acids $(100 \mu \mathrm{mol}$ total) was prepared from stock solutions treated with a solution of HBTU, HOBT, and DIEA as described above for the generation of DNA libraries (chemset 5). The resulting solution was added to peptide resin $\mathbf{1 0}$ in a polypropylene reaction vial, and the coupling was allowed to proceed for $60 \mathrm{~min}$, with vortexing every $5 \mathrm{~min}$. The resin was rinsed with DMF $(2 \times 1.5 \mathrm{~mL})$, $\mathrm{CH}_{2} \mathrm{Cl}_{2}(2 \times 1 \mathrm{~mL})$, and $\mathrm{MeOH}(2 \times 1.5 \mathrm{~mL})$ and dried at 0.1 Torr. A mixture of TFA $(90 \mu \mathrm{L})$, (TIPS, $5 \mu \mathrm{L})$, and water ( $5 \mu \mathrm{L}$ ) was added to the resin, followed by vortexing and centrifugation. After $11 \mathrm{~h}$, the supernatant was dripped into cold diethyl ether, followed by centrifugation. The precipitate was treated with fresh diethyl ether, again followed by centrifugation. The supernatant was aspirated, and the residue was dissolved in water, followed by lyophilization to dryness. The residue was taken up in water $(30 \mu \mathrm{L})$, and an aliquot ( $1 \mu \mathrm{L}$ ) was analyzed via MALDI-TOFMS using the same matrix conditions as for the porphyrin libraries.

Acknowledgment. The authors thank Jan Rojas for help with mass spectrometry and William H. Connors for sharing early results from his work. This work was supported in part by Deutsche Forschungsgemeinschaft (Grant no. RI 1063/ 1-2) and The University of Constance.

Supporting Information Available. Brief description of the mathematical approach used to calculate relative reactivities from the results of assay 2 and MALDI-TOF mass spectrum of a library of general structure chemset 5 prepared with a mixture of 21 activated acids ( 3 pages). This material is available free of charge via the Internet at http:// pubs.acs.org.

\section{References and Notes}

(1) (a) Mayr, H.; Kuhn, O.; Patz, M. J. Phys. Org. Chem. 1998, 11, 642-654. (b) Hansch, C. Acc. Chem. Res. 1993, 26, $147-153$.

(2) One such database is available from Accelrys. A brief description can be found on the Internet at http://www.accelrys.com/chem_db/failedreact html.

(3) Congreve, M. S.; Jamieson, C. Drug Discovery Today 2002, 7, 139-142.

(4) Ostresh, J. M.; Winkle, J. H.; Hamashin, V. T.; Houghten, R. A. Biopolymers 1994, 34, 1681-1689.

(5) (a) Ragnarsson, U.; Karlsson, S.; Sandberg, B. Acta Chem. Scand. 1971, 25, 1487-1489. (b) Ragnarsson, U.; Karlsson, S.; Sandberg, B. J. Org. Chem. 1974, 39, 3837-3841.

(6) Gerritz, S. W.; Trump, R. P.; Zuercher, W. J. J. Am. Chem. Soc. 2000, 122, 6357-6363. 
(7) Selected references: (a) Look, G. C.; Holmes, C. P.; Chinn, J. P.; Gallop. M. A. J. Org. Chem. 1994, 59, 7588-7590. (b) Garigipati, R. S.; Adams, B.; Adams, J. L.; Sarkar, S. K. J. Org. Chem. 1996, 61, 2911-2914. (c) Lin, M.; Shapiro, M. J. J. Org. Chem. 1996, 61, 7617-7619. (d) Sarkar, S. K.; Garigipati, R. S.; Keifer, P. A. J. Am. Chem. Soc. 1996, 118, 2305-2306.

(8) Haap, W. J.; Redemann, T.; Früchtel, J. S.; Jung, G. G.I.T. Lab. J. 1997, 94-98.

(9) Selected references: (a) Stevanovic, S.; Wiesmüller, K.-H.; Metzger, J.; Beck-Sickinger, A. G.; Jung, G. Bioorg. Med. Chem. Lett. 1993, 3, 431-436. (b) Egner, B. J.; Langley, G. J.; Bradley, M. J. Org. Chem. 1995, 60, 2652-2653. (c) Boutin, J. A.; Hennig, P.; Lambert, P. H.; Bertin, S.; Petit, L.; Mahieu, J. P.; Serkiz, B.; Volland, J. P.; Fauchere, J.-L. Anal. Biochem. 1996, 234, 126-141. (d) Geysen, H. M.; Wagner, C. D.; Bodnar, W. M.; Markworth, C. J.; Parke, G. J.; Schoenen, F. J.; Wagner, D. S.; Kinder, D. S. Chem. Biol. 1996, 3, 679-688. (e) Fitzgerald, M. C.; Harris, K.; Shevlin, C. G.; Siuzdak, G. Bioorg. Med. Chem. Lett. 1996, 6, 979982. (f) Pomerantz, S. C.; McCloskey, J. A.; Tarasow, T. M.; Eaton, B. E. J. Am. Chem. Soc. 1997, 119, 3861-3867. (g) Hughes, I. J. Med. Chem. 1998, 41, 3804-3811. (h) Yates, N.; Wislocki, D.; Roberts, A.; Berk, S.; Klatt, T.; Shen, D.-M.; Willoughby, C.; Rosauer, K.; Chapman, K.; Griffin, P. Anal. Chem. 2001, 73, 2941-2951.

(10) Selected references: (a) Gao, J.; Cheng, X.; Chen, R.; Sigal, G. B.; Bruce, J. E.; Schwartz, B. L.; Hofstadler, S. A.; Anderson, G. A.; Smith, R. D.; Whitesides, G. M. J. Med. Chem. 1996, 39, 1949-1955. (b) Wu, Q.; Gao, J.; JosephMcCarthy, D.; Sigal, G. B.; Bruce, J. E.; Whitesides, G. M.; Smith, R. D. J. Am. Chem. Soc. 1997, 119, 1157-1158. (c) Kupke, T.; Kempert, C.; Jung, G.; Goetz, F. J. Biol. Chem. 1995, 270, 11282-11289.

(11) Matrix suppression effects can sometimes be exploited to overcome this limitation. See, for example: (a) Knochenmuss, R.; Dubois, F.; Dale, M. J.; Zenobi, R. Rapid Commun. Mass Spectrom. 1996, 10, 871-877. (b) Knochenmuss, R.; Karbach, V.; Wiesli, U.; Breuker, K.; Zenobi, R. Rapid Commun. Mass Spectrom. 1998, 12, 529-534, and references therein.

(12) Tang, K.; Allman, S. L.; Jones, R. B.; Chen, C. H. Anal. Chem. 1993, 65, 2164-2166.

(13) Gusev, A. I.; Wilkinson, W. R.; Proctor, A.; Hercules, D. M. Anal. Chem. 1995, 67, 1034-1041.

(14) (a) Harvey, D. J. Rapid Commun. Mass Spectrom. 1993, 7, 614-618. (b) Nelson, R. W.; McLean, M. A.; Hutchens, T. W. Anal. Chem. 1994, 66, 1408-1415.

(15) Sarracino, D.; Richert, C. Bioorg. Med. Chem. Lett. 1996, 6, 2543-2548.

(16) Dombi, K. L.; Richert, C. Molecules 2000, 5, 1265-1280.

(17) (a) Bettelheim, A.; White, B. A.; Raybuck, S. A.; Murray, R. W. Inorg. Chem. 1987, 26, 1009-1017. (b) Bookser, B. C.; Bruice, T. C. J. Am. Chem. Soc. 1991, 113, 4208-4218.

(18) Berlin, K.; Jain, R. K.; Tetzlaff, C.; Steinbeck, C.; Richert, C. Chem. Biol. 1997, 4, 63-77.

(19) Pieles, U.; Zürcher, W.; Schär, M.; Moser H. E. Nucleic Acids Res. 1993, 21, 3191-3196.

(20) Schwope, I.; Bleczinski, C. F.; Richert, C. J. Org. Chem. 1999, 64, 4749-4761.

(21) Isaacs, N. Physical Organic Chemistry, 2nd ed.; AddisonWesley Longman: Harlow, U.K., 1995; pp 152-153 (averaged substituent constants).

(22) Altman, R. K.; Schwope, I.; Sarracino, D. A.; Tetzlaff, C. N.; Bleczinski, C. F.; Richert, C. J. Comb. Chem. 1999, 1, 493-508.
(23) (a) Churchill, M. E. A.; Travers, A. A. Trends Biochem. Sci. 1991, 16, 92-97. (b) Suzuki, M. EMBO J. 1989, 8, 797804. (c) Takeuchi, H.; Sasamori, J. Biopolymers 1995, 35, $359-367$.

(24) The mixing procedure employed in these exploratory experiments did not avoid errors due to evaporation as carefully as desirable. Since subsequent experiments showed that the desorption/ionization bias of relative reactivity values were apparently not the main cause for poor incorporation data, these experiments were not repeated with a further improved protocol.

(25) Connors, W. H.; Narayanan, S.; Brotzel, F.; Richert, C. Unpublished results.

(26) Carpino, L. A.; Ionescu, D.; El-Faham, A.; Henklein, P.; Wenschuh, H.; Bienert, M.; Beyermann, M. Tetrahedron Lett. 1998, 39, 241-244.

(27) Janda, K. D. Proc. Natl. Acad. Sci. U.S.A. 1994, 91, 1077910785.

(28) Brummel, C. L.; Vickerman, J. C.; Carr, S. A.; Hemling, M. E.; Roberts, G. D.; Johnson, W.; Weinstock, J.; Gaitanopoulos, D.; Benkovic, S. J.; Winograd, N. Anal. Chem. 1996, 68, 237-242.

(29) Erb, E.; Janda, K. D.; Brenner, S. Proc. Natl. Acad. Sci. U.S.A. 1994, 91, 11422-11426.

(30) Schneider, K.; Chait, B. T. Org. Mass Spectrom. 1993, 28, $1353-1361$

(31) (a) Liao, P.-C.; Allison, J. J. Mass Spectrom. 1995, 30, 408423. (b) Knochenmuss, R.; Stortelder, A.; Breuker, K.; Zenobi, R. J. Mass Spectrom. 2000, 35, 1237-1245.

(32) (a) Kryatova, O. P.; Connors, W. H.; Bleczinski, C. F.; Mokhir, A. A.; Richert, C. Org. Lett. 2001, 3, 987-990. (b) Bleczinski, C. F.; Richert, C. J. Am. Chem. Soc. 1999, 121, 10889-10894.

(33) (a) Henderson, B. W.; Dougherty, T. J. Photodynamic Therapy; Marcel Dekker: New York, 1992. (b) Porphyrin Photosensitization; Kessel, D., Dougherty, J., Eds.; Plenum Press: New York, 1983.

(34) Bonnett, R.; Martinez, G. Org. Lett. 2002, 4, 2013-2016.

(35) Ref 3 in ref 27.

(36) (a) Berlin, K.; Jain, R. K.; Richert, C. Biotechnol. Bioeng.. Comb. Chem. 1998, 61, 107-118. (b) Drain, C. M.; Gong, X.; Ruta, V.; Soll, C. E.; Chicoineau, P. F. J. Comb. Chem. 1999, 1, 286-290.

(37) (a) Fiel, R. J.; Howard, J. C.; Mark, E. H.; Datta-Gupta, N. Nucleic Acids Res. 1979, 6, 3093-3118. (b) Bustamante, C.; Gurrieri, S.; Pasternack, R. F.; Purrello, R.; Rizzarelli, E. Biopolymers 1994, 34, 1099-1104. (c) Jain, R. K. Sarracino, D. A.; Richert, C. Chem. Commun. 1998, 423424.

(38) See, for example: (a) Collman, J. P.; Wang, Z. Chemtracts 1999, 229-263. (b) Rakow, N. A.; Suslick, K. S. A Nature 2000, 406, 710-713. (c) Kimura, M.; Shiba, T.; Yamazaki, M.; Hanabusa, K.; Shirai, H.; Kobayashi, N. J. Am. Chem. Soc. 2001, 123, 5636-5642.

(39) The term "delayed extraction" is used synonymously with "time lag focusing" and "pulsed-ion extraction".

(40) Some early assays were performed with $0.4 \mathrm{mg}(0.418 \mu \mathrm{mol})$ of $\mathbf{2} \mathbf{b}$ and with weighing out of the acids for every individual assay. These gave similar results, but used more of the porphyrin and were more time-consuming. 